\title{
The Requirement of Inorganic Fe-S Clusters for the Biosynthesis of the Organometallic Molybdenum Cofactor
}

\author{
Ralf R. Mendel ${ }^{1}$, Thomas W. Hercher ${ }^{1}$, Arkadiusz Zupok ${ }^{2}$, Muhammad A. Hasnat ${ }^{2}$ \\ and Silke Leimkühler ${ }^{2, *}$ \\ 1 Institute of Plant Biology, Braunschweig University of Technology, Humboldtstr. 1, 38106 Braunschweig, \\ Germany; r.mendel@tu-bs.de (R.R.M.); t.hercher@tu-bs.de (T.W.H.) \\ 2 Department of Molecular Enzymology, Institute of Biochemistry and Biology, University of Potsdam, \\ Karl-Liebknecht-Str. 24-25, 14476 Potsdam, Germany; zupok@uni-potsdam.de (A.Z.); \\ hasnat@uni-potsdam.de (M.A.H.) \\ * Correspondence: sleim@uni-potsdam.de; Tel.: +49-331-977-5603; Fax: +49-331-977-5128
}

Received: 18 June 2020; Accepted: 14 July 2020; Published: 16 July 2020

\begin{abstract}
Iron-sulfur (Fe-S) clusters are essential protein cofactors. In enzymes, they are present either in the rhombic [2Fe-2S] or the cubic [4Fe-4S] form, where they are involved in catalysis and electron transfer and in the biosynthesis of metal-containing prosthetic groups like the molybdenum cofactor (Moco). Here, we give an overview of the assembly of Fe-S clusters in bacteria and humans and present their connection to the Moco biosynthesis pathway. In all organisms, Fe-S cluster assembly starts with the abstraction of sulfur from L-cysteine and its transfer to a scaffold protein. After formation, Fe-S clusters are transferred to carrier proteins that insert them into recipient apo-proteins. In eukaryotes like humans and plants, Fe-S cluster assembly takes place both in mitochondria and in the cytosol. Both Moco biosynthesis and Fe-S cluster assembly are highly conserved among all kingdoms of life. Moco is a tricyclic pterin compound with molybdenum coordinated through its unique dithiolene group. Moco biosynthesis begins in the mitochondria in a Fe-S cluster dependent step involving radical/S-adenosylmethionine (SAM) chemistry. An intermediate is transferred to the cytosol where the dithiolene group is formed, to which molybdenum is finally added. Further connections between Fe-S cluster assembly and Moco biosynthesis are discussed in detail.
\end{abstract}

Keywords: Moco biosynthesis; Fe-S cluster assembly; L-cysteine desulfurase; ISC; SUF; NIF; iron; molybdenum; sulfur

\section{Introduction}

As one of the most abundant metals on earth, iron naturally is one of the prevalent metal ions in biological systems [1]. Iron is a major constituent of iron-sulfur (Fe-S) clusters and plays an important role in life on earth. Fe-S centers are essential protein cofactors in all forms of life [2]. They are involved in many key biological pathways including the metabolism of carbon, nitrogen and sulfur, photosynthesis, respiration, biosynthesis of antibiotics, protein translation, replication and DNA repair, gene regulation, protection from oxidizing agents, and neurotransmission. In particular, Fe-S centers are not only involved as enzyme cofactors in catalysis and electron transfer, but they have been revealed to be essential for the assembly of other metal-containing cofactors.

The most common clusters are [2Fe-2S], [3Fe-4S], and [4Fe-4S], and they are the most versatile and presumably oldest cofactors of proteins in the cell (Figure 1). Their synthesis and insertion into apo-proteins require the function of complex cellular machinery [2-4]. In addition to the roles named above, Fe-S cluster-containing proteins play critical roles in the assembly of other metal-containing 
enzymes or metal-containing cofactors such as the molybdenum cofactor (Moco). In this case, Fe-S cluster assembly has to precede the biosynthesis of this metal-dependent molecule.

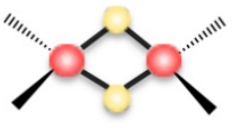

[2Fe-2S]

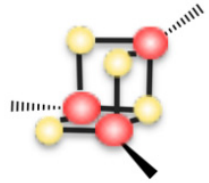

[3Fe-4S]

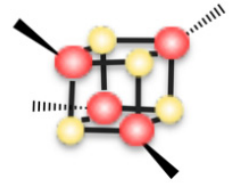

[4Fe-4S]

Figure 1. Three common types of Fe-S clusters. Shown are the structures of a rhombic [2Fe-2S] and a cubane $[4 \mathrm{Fe}-4 \mathrm{~S}]$ cluster. The [3Fe-4S] cluster can be generated by the loss of iron from a [4Fe-4S] cluster. Sulfur is symbolized in yellow and iron is represented in red.

Fe-S clusters were first discovered in the early 1960s by H. Beinert, R.H. Sands, and others, in photosynthetic organisms [5], nitrogen-fixing bacteria [6], and sub-mitochondrial fractions of mammalian origin [7]. To date, numerous different types of proteins or enzymes containing diverse Fe-S clusters have been identified [2]. Fe-S containing proteins are ubiquitous and unarguably constitute the oldest but the structurally-heterogeneous class of proteins in biology. Fe-S enzymes are quite diverse in function and many of them catalyze key redox reactions in central metabolism under both aerobic and anaerobic conditions. Fe-S clusters can form spontaneously in solution from $\mathrm{Fe}^{2+} / \mathrm{Fe}^{3+}$,

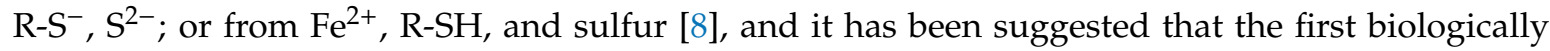
meaningful reactions were catalyzed by Fe-S clusters [9]. Presumably, the first Fe-S proteins arose from the incorporation of preformed inorganic Fe-S clusters into polypeptides. In the world as we currently know it, the process of Fe-S cluster biosynthesis in living organisms turns out to be highly regulated and is catalyzed by numerous biogenesis factors that are remarkably conserved among prokaryotes and eukaryotes $[4,10]$.

The complexity of Fe-S cluster biosynthesis became evident in 1998, when a complex gene cluster was discovered in bacteria that codes for proteins that are involved in their controlled assembly [11]. In eukaryotes, the mitochondria were identified as the primary compartment for Fe-S cluster assembly and were found to contain a very similar system as found in prokaryotes [12]. Since the late 1990s, the proteins involved in Fe-S cluster biosynthesis have been studied and characterized extensively. While these studies provided a general outline of in vitro and in vivo Fe-S cluster assembly, a number of major questions remain to be answered. Remaining gaps in our knowledge are: how Fe-S clusters are transferred to their target proteins, how specificity in this process is achieved and, in particular, how the iron for cluster assembly is provided in the cell.

Among the most recent additions to the field of Fe-S dependent enzymes was the discovery of the superfamily of radical/S-adenosylmethionine (radical/SAM) enzymes in 2001 [13]. These enzymes utilize a [4Fe-4S] cluster and SAM to initiate a diverse set of radical reactions, in most cases via the generation of a $5^{\prime}$-deoxyadenosyl radical intermediate. While this superfamily has been already identified in 2001 by studies that were mainly based on bioinformatics, the discovery of new Fe-S containing enzymes that employ SAM to initiate radical reactions still continues. Especially in recent years, it has become obvious that most reaction pathways for the synthesis of complex metal-containing cofactors have recruited radical/SAM chemistry [14]. One example has been the identification of the mechanism of the radical/SAM enzyme MoaA, a GTP 3',8-cyclase in the biosynthesis of Moco of the diverse class of molybdoenzymes $[15,16]$. The number of known radical/SAM-dependent enzymes grew exponentially during the last years, with an initial identification of 600 members of the superfamily by Sofia et al. in 2001 that until today has increased to more than 113,000 members [14]. These enzymes are found across species and catalyze a diverse set of reactions, the vast majority of which have yet to be characterized. Due to their functional diversity, most cellular processes depend on this superfamily of [4Fe-4S]-containing enzymes. 


\section{The Assembly of Fe-S Clusters in Bacteria}

Three main Fe-S cluster assembly pathways have been identified to date, namely the NIF (nitrogen fixation) system, the SUF (uu fur formation) system, and the ISC (iron sulfur cluster) system (reviewed in Reference [4]) (Figure 2). The three systems have different phylogenetic distributions throughout the three kingdoms of life. For example, in cyanobacteria, the SUF pathway is the major system for Fe-S cluster assembly, while in Escherichia coli the ISC has the predominant role, while the SUF pathway is more important under stress conditions [17]. Furthermore, in gram-positive pathogens such as Mycobacteria or Clostridia, as well as some Archaea, the SUF pathway is essential. In other bacteria like the plant-pathogenic bacterium Dickeya dandatii, all three ISC, SUF, and NIF systems are present [18]. In eukaryotes, the Fe-S cluster assembly pathway is further complicated by a different localization to specific organelles [19]. Homologues of the ISC pathway are present predominantly in mitochondria, while SUF homologues are restricted to the chloroplasts of some photosynthetic organisms (Figure 2). In addition, a cytosolic iron sulfur cluster (CIA) machinery is present that appears to be distinct from the SUF and ISC pathway.
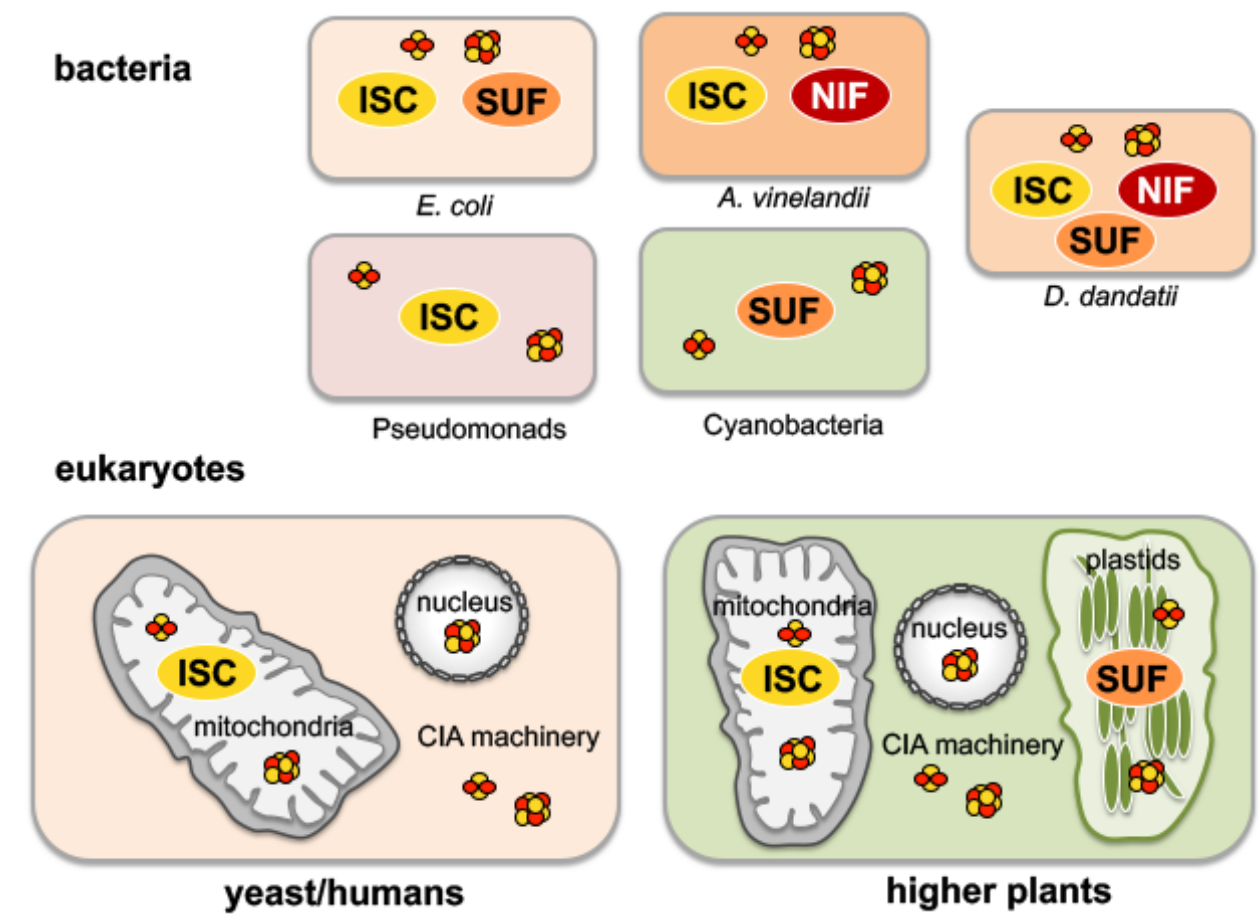

Figure 2. Possible links of Fe-S cluster assembly systems in prokaryotes and eukaryotes. Bacterial organisms harbor different complements of the NIF (nitrogen fixation), ISC (iron-sulfur cluster), and SUF (sulfur mobilization) systems. The NIF system is specialized for the assembly of nitrogenase in azototrophic bacteria. In bacteria like E. coli, both the ISC and SUF systems are present, while Pseudomonads contain only the ISC system and Cyanobacteria contain only the SUF system, and in Dickeya dandatii all three systems are present. The ISC assembly machinery of mitochondria is likely inherited from an ancestor of $\alpha$-proteobacteria, the evolutionary origin of these organelles. The SUF machinery of plastids in higher plants has been likely inherited by endosymbiosis of a photosynthetic bacterium. The cytosolic iron-sulfur protein assembly (CIA) machinery for the maturation of cytosolic and nuclear Fe-S proteins depends on the mitochondrial ISC assembly machinery. These three systems are highly conserved in eukaryotes from humans to yeast and plants.

Fe-S clusters are mainly bound to proteins by cysteine or histidine residues either in the rhombic [2Fe-2S] or the cubic [4Fe-4S] forms (Figure 1) [20]. In model organisms, like E. coli, the Fe-S cluster assembly pathways have been well studied. E. coli possesses two systems for Fe-S cluster assembly, which share the same basic principles in cluster assembly. While the ISC machinery is transcribed 
by the iscRSUA-hscBA-fdx-iscX operon, the SUF machinery is organized in the sufABCDSE operon (Figure 3) [21-23]. As a starting point, the L-cysteine desulfurases IscS or SufS convert L-cysteine to L-alanine and provide the sulfur in the form of a protein-bound persulfide [23]. IscS was shown to act as housekeeping L-cysteine desulfurase [11], while SufS acts under conditions of iron-limitation and oxidative stress [24]. For house-keeping Fe-S cluster assembly, IscS interacts with IscU, thereby making IscU accessible to receive the persulfide sulfur from IscS. In this step, IscU serves as a scaffold protein for the initial assembly of [2Fe-2S] clusters and [4Fe-4S] clusters (Figure 3) [25,26]. The iron source for nascent Fe-S cluster formation has not been identified yet; however, several proteins have been discussed as candidates [27]. IscS and IscU proteins form a heterotetrameric complex together with CyaY, the bacterial homologue to frataxin (see below) [26,28]. During this step of the assembly of Fe-S clusters electrons are required for persulfide reduction. These electrons are most likely provided by ferredoxin ( $\mathrm{Fdx}$ ) [29-31]. Initially, one [2Fe-2S] cluster is formed per IscU monomer inducing a conformational change within the IscU protein that decreases the stability of the IscS-IscU interaction [23]. This step is expected to further enable the reductive coupling of two [2Fe-2S] clusters to form one single [4Fe-4S] cluster on IscU.

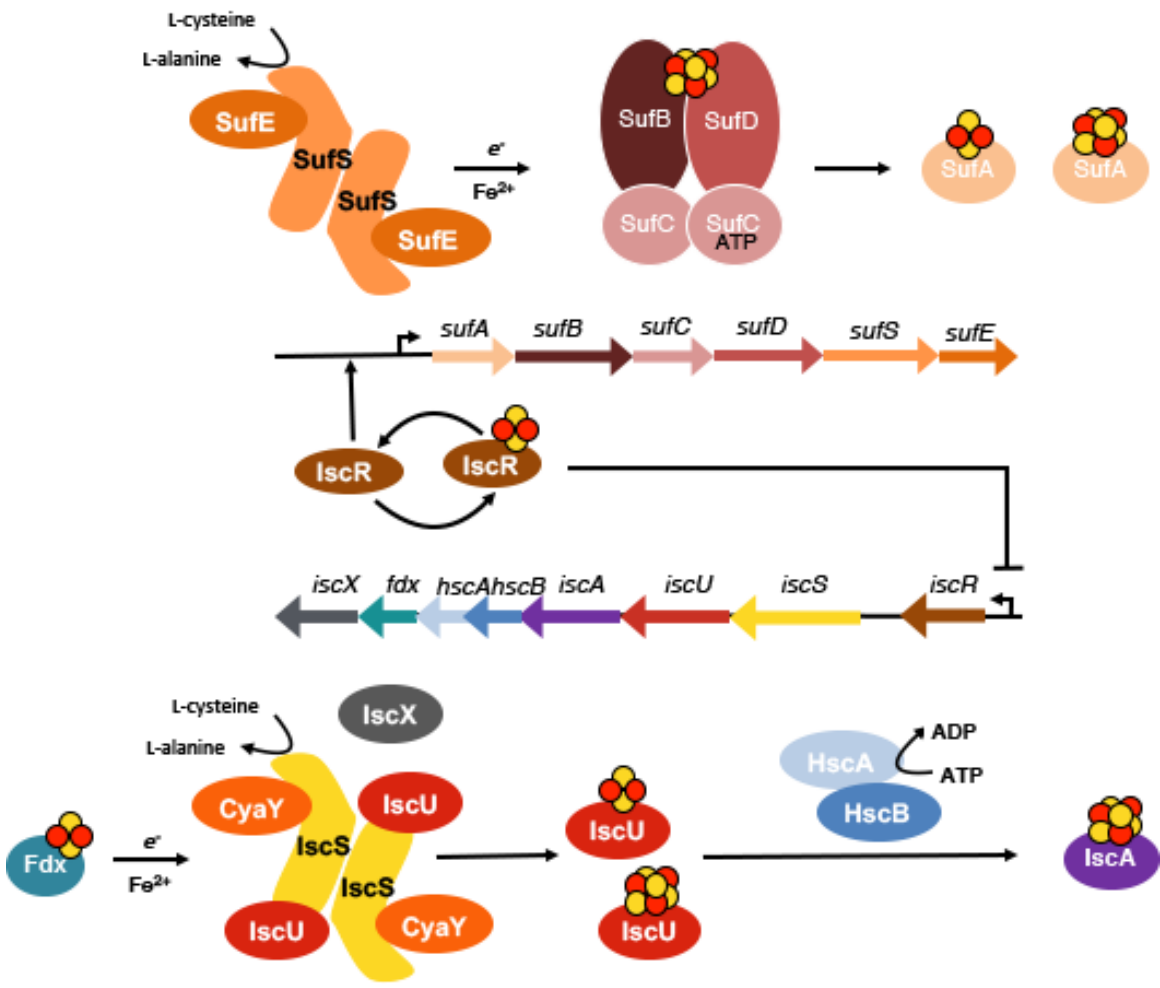

Figure 3. A model for the assembly of Fe-S clusters in E. coli by the ISC and SUF machinery. For each system, the proteins involved in each step are indicated in addition to their operon organization. The building of the Fe-S clusters in both systems is facilitated by the scaffold proteins IscU or SufB. After the formation of [2Fe-2S] or [4Fe-4S] clusters on IscU, their release is catalyzed with the help of the HscBA co/chaperones in the ISC system. This step in particular still needs to be clarified in the SUF machinery. After formation, the clusters are transferred by the A-type carrier proteins IscA and SufA to target proteins. Both systems are tightly regulated by IscR at the level of Fe-S cluster availability. Under normal conditions, the IscR regulator exists in an [2Fe-2S] cluster bound form and represses its own expression to control Fe-S cluster formation and the Fe-S state of the cell. Under iron limitation, the IscR regulator is accumulated and converted to its apo-form that activates the suf operon. The model shows a simplified version of the regulation of both systems, not depicting the regulation by small RNAs or oxygen. 
For the release of Fe-S clusters from IscU, HscA, and $\mathrm{HscB}$ are involved in an ATP-dependent manner, two members of the DnaK/DnaJ chaperones/co-chaperone family [32]. HscA recognizes a specific motif on IscU, and their interaction is additionally regulated by the co-chaperone, HscB. The mechanism by which the chaperone facilitates cluster release from IscU has been proposed to involve two conformational states of IscU with different affinities to the bound Fe-S clusters [33]. The chaperones thereby favor the low-affinity IscU state and facilitate the release of the Fe-S cluster from IscU.

In comparison, the SUF system has also been well characterized from studies in bacteria [4,24,34-37]. Here, SufS forms a complex with SufE, which together mobilize the sulfur for cluster assembly. In the SUF machinery, SufB is the Fe-S scaffold protein that acts in conjunction with SufC (and in some cases additionally with SufD) [38]. After Fe-S cluster formation, SufA then transfers the Fe-S clusters to target apo-proteins [39] (Figure 3).

Numerous Fe-S carriers have been identified in both prokaryotes and eukaryotes [4]. These include as main carriers the so-called A-type carriers (ATC) IscA, SufA, and ErpA (Figure 4) [40,41]. Other carriers include the highly-conserved NFU-type proteins [42], the monothiol glutaredoxins (Grx 5 in yeast and GrxD in E. coli) [43,44], or the P-loop NTPases, (Ind1 in mitochondria, ApbC in Salmonella) $[45,46]$.

Previous phylogenetic studies had classified ErpA and IscA into two different families; while ErpA belongs to family ATC-I, IscA was grouped into family ATC-II [40]. While ATC-I family members interact with the apo-target proteins, the ATC-II family members are predicted to interact with the scaffold proteins instead. However, the ATC proteins were also shown to replace each other in their roles.

The expression of the SUF and ISC system has been revealed to be tightly regulated in E. coli. While the ISC system is the house-keeping Fe-S cluster assembly system, the SUF system instead is mainly synthesized under iron-limiting conditions [24]. One of the main regulators that regulate the expression of either the ISC system or the SUF system is the IscR protein [4]. IscR is a transcriptional regulator that exists in the apo-form and in a [2Fe-2S] cluster bound form in the cell [47]. In its [2Fe-2S] cluster bound form, IscR represses its own expression in addition to that of iscRSUA-hscBA-fdx-iscX. In contrast, in its apo-form, IscR activates the expression of the SUF system (Figure 3) [4]. This mechanism allows IscR to fine-tune Fe-S cluster synthesis in response to the presence of synthesized Fe-S clusters and iron availability in the cell. 


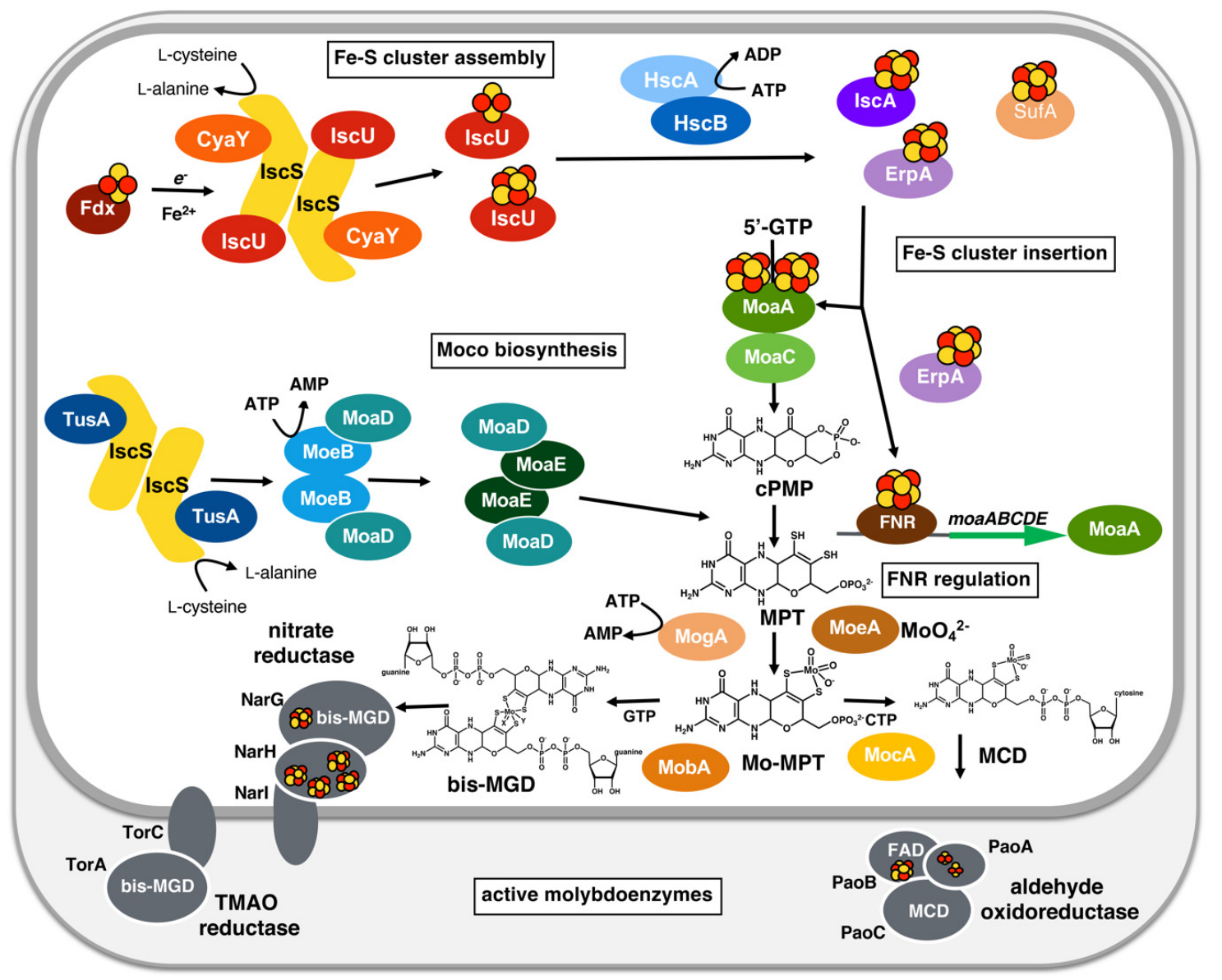

Figure 4. Moco biosynthesis and the link to Fe-S cluster assembly in E. coli. In Moco biosynthesis, Mo-MPT is formed from 5'GTP with cPMP and MPT as stable intermediates. For enzymes of the DMSO reductase family like TorCA or NarGHI, bis-MGD is formed by the addition of GMP to each MPT unit in the bis-Mo-MPT intermediate. For enzymes like PaoABC, Mo-MPT is further modified by the addition of CMP to form the MCD form of the cofactor. Molybdoenzymes, in general, are complex enzymes, containing additional cofactors like FAD, Fe-S clusters, or hemes. The sulfur for the synthesis of the dithiolene group in Moco is mobilized by IscS with the additional involvement of the TusA protein. CyaY interacts with the IscS-IscU complex and forms a central heterotetramer. Fe-S clusters assemble on the scaffold protein IscU, which receives the sulfur from the L-cysteine desulfurase IscS. Assembly and release of the clusters is catalyzed by the chaperones HscAB. Ferredoxin is delivering the electrons. The carrier proteins IscA and ErpA deliver the matured Fe-S clusters to recipient protein among which is MoaA in Moco biosynthesis.

\section{A General Scheme for the Biosynthesis of the Molybdenum Cofactor}

The biosynthesis of the molybdenum cofactor (Moco) is highly conserved among all kingdoms of life. The chemical nature of Moco was first determined by Rajagopalan and coworkers in 1982 [48]. The pathway for the biosynthesis can generally be divided into three steps, with the characteristic of each step being the formation of a stable intermediate (Figure 4) [49-52]. The first step represents the synthesis of cyclic pyranopterin monophosphate (cPMP) from 5'-GTP [53], the second step the introduction of two sulfur atoms into cPMP forming molybdopterin (MPT) by [54], and the third step is the insertion of molybdate into MPT, resulting in the formation of the so-called Mo-MPT cofactor [55]. In prokaryotes, Mo-MPT is further modified by the attachment of GMP or CMP to the phosphate group of MPT, forming the two dinucleotide variants of Moco, MPT-guanine dinucleotide (MGD), [56] and MPT-cytosine dinucleotide (MCD) [57,58] (Figure 4). The characteristics of different forms of Moco are represented further by different ligands at the molybdenum atom. This resulted in the categorization 
of molybdoenzymes into three families (Figure 5): the xanthine oxidase (XO) family, the sulfite oxidase (SO) family, and the dimethyl sulfoxide (DMSO) reductase family. Enzymes of the DMSO reductase family generally contain two MPT moieties ligated to the molybdenum atom and are present only in prokaryotes [50]. Here, we will briefly summarize the biosynthesis of Moco.

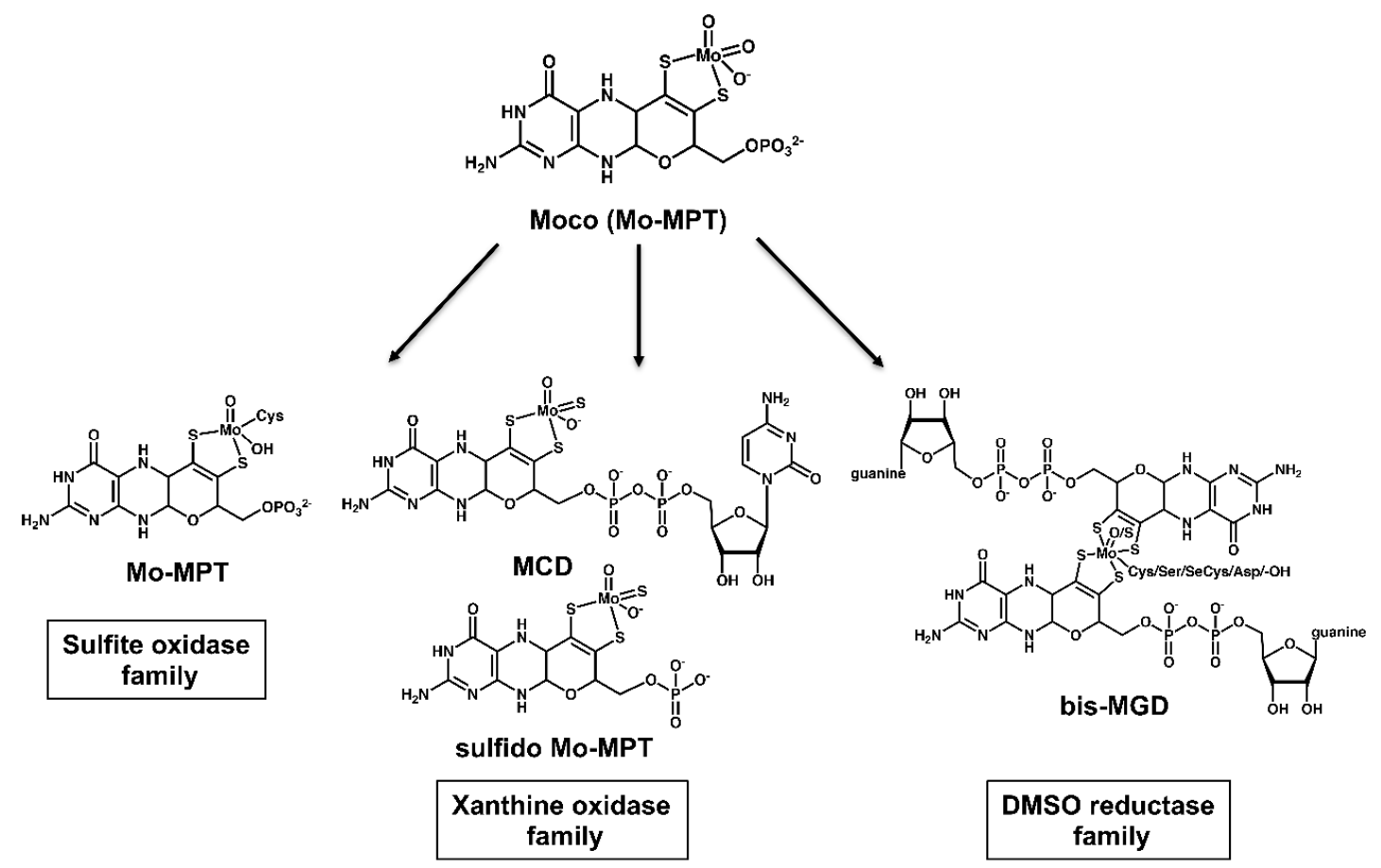

Figure 5. The three families of molybdoenzymes in pro- and eukaryotes. Moco exists in different variants and is divided into three enzyme families. The basic form of Moco is Mo-MPT that coordinates the molybdenum atom in a tri-oxo form. The SO family is present both in pro-and eukaryotes and is characterized by a molybdenum ligation with one oxo-, one hydroxide- and one cysteine ligand from the protein backbone. The $\mathrm{XO}$ family is also present in both pro- and eukaryotes and is characterized by an equatorial sulfido-ligand, an apical oxo ligand, and one hydroxide or $\mathrm{O}^{-}$ligand. The $\mathrm{XO}$ family contains the sulfurated form of Mo-MPT. In E. coli, an additional nucleotide is present in this family, forming the molybdopterin cytosine dinucleotide cofactor (MCD). The DMSO reductase family contains two MPTs (bis-Mo-MPT) or two MGDs (bis-MGD) ligated to one molybdenum atom with additional ligands being an $\mathrm{O} / \mathrm{S}$ and a sixth ligand which can be a serine, a cysteine, a selenocysteine, an aspartate or a hydroxide ligand.

In the first step of Moco biosynthesis, $5^{\prime}$-GTP is converted to cPMP (Figure 4) [53]. cPMP is a 6-alkyl pterin with a cyclic phosphate group at the $\mathrm{C}^{\prime}$ and $C 4^{\prime}$ atoms [59]. This reaction is catalyzed by two enzymes, MoaA and MoaC [53,60] (Figure 4). While the individual catalytic functions of MoaA and MoaC have long been unknown, recent studies showed that MoaA catalyzes the conversion

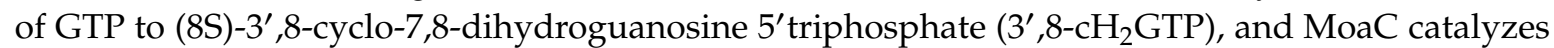
the conversion of $3^{\prime}, 8-\mathrm{cH}_{2}$ GTP to cPMP [15]. Details of the recent updates and the details of MoaA mechanism, where [4Fe-4S] clusters play central roles, will be discussed in the next chapter.

In the second step of Moco biosynthesis, two sulfur atoms are inserted into CPMP, and MPT is formed as a stable intermediate [54,61-65]. This reaction is catalyzed by MPT synthase, composed of two MoaD and two MoaE subunits (Figure 4) [66]. The sulfur atoms required for this reaction are present at the C-terminus of MoaD in form of a thiocarboxylate group $[67,68]$. Studies on the reaction mechanism showed that the first sulfur is added at the C2' position of $\mathrm{CPMP}$ in a reaction that is coupled to the hydrolysis of the cPMP cyclic phosphate group [65]. The second sulfur is then transferred to the $\mathrm{C}^{\prime}$ of the hemisulfurated intermediate and MPT is formed as the product. 
In the third step of Moco biosynthesis, molybdate is inserted to the dithiolene sulfurs of MPT and Mo-MPT is formed, one of the forms of Moco. The specific insertion of molybdenum into MPT is catalyzed by the joined action of MoeA and MogA (Figure 4) [69,70]. MogA thereby hydrolyzes ATP and forms the activated MPT-AMP intermediate [71]. This intermediate is then transferred to MoeA, which mediates molybdenum ligation at low concentrations of $\mathrm{MoO}_{4}{ }^{2-}$ [70]. Mo-MPT can be further modified by nucleotide addition in the next step of Moco biosynthesis, which is present only in prokaryotes (Figure 5) [72]. Alternatively, the Mo-MPT cofactor can be directly inserted into enzymes of the SO family. In this family, the molybdenum atom of Mo-MPT is coordinated by a cysteine from the polypeptide backbone of the protein, representing the cofactor in its $\mathrm{MPT}-\mathrm{Mo}^{\mathrm{VI}} \mathrm{O}_{2}$ form [50].

The proteins of the DMSO reductase family in bacteria contain the bis-MGD cofactor (Figure 5) [50]. The synthesis of the bis-MGD was shown to occur in a two-step reaction catalysed by MobA using Mo-MPT and Mg-GTP as substrates [72]. In the first reaction, the bis-Mo-MPT intermediate is formed on MobA from two Mo-MPT molecules [73]. In the second reaction, two GMP moieties from GTP are added to the $\mathrm{C}^{\prime}$ ' phosphate of bis-Mo-MPT, forming the bis-MGD cofactor [74,75]. After the formation of bis-MGD, the cofactor can be released from MobA and inserted into target enzymes. However, it is expected that bis-MGD does not exist in a free form in the cell. Formed bis-MGD is rather expected to be immediately recruited by Moco-binding chaperones that protect the cofactor from oxidation and specifically interact with their target apo-molybdoenzymes for bis-MGD insertion. After insertion, bis-MGD is generally ligated by a serine, a cysteine, a selenocysteine, or an aspartate from the protein backbone. The other ligand in enzymes of the DMSO reductase family that bind the bis-MGD cofactor is an oxo- or sulfido atom.

The addition of CMP results in the formation of the MPT-cytosine dinucleotide (MCD) cofactor [58], a cofactor that is present in the xanthine oxidase family of molybdoenzymes in bacteria (Figure 5). The formation of MCD is catalyzed by MocA (Moco cytidylyltransferase). After the formation of MCD and the bis-MGD cofactor, a further modification at the molybdenum atom can occur by the addition of a terminal sulfido-ligand [76]. The sulfido-ligand at the equatorial position of the molybdenum atom is a characteristic feature of enzymes in the xanthine oxidase family. In eukaryotes, enzymes of this family do not harbor the additional CMP modification of the cofactor (Figure 5).

\section{Linking Moco Biosynthesis and Fe-S Cluster Assembly in Bacteria}

More than 60 different Moco-containing molybdoenzymes have been identified to date [77]. In recent years it has become evident that the biosynthesis of Moco and the assembly of Fe-S clusters are directly connected to each other. Moco biosynthesis directly depends on the presence of Fe-S clusters or components of the Fe-S cluster assembly machinery on several levels (Figure 4). Many molybdoenzymes bind Fe-S clusters as additional cofactors that are involved in intramolecular electron transfer reactions. In Moco biosynthesis, the MoaA protein harbors two [4Fe-4S] clusters and thus directly depends on Fe-S cluster assembly. In addition, the L-cysteine desulfurase IscS is shared between Fe-S cluster assembly and Moco biosynthesis since it also mobilizes the sulfur for the synthesis of the dithiolene group present in Moco. Further, the expression of most molybdoenzymes and proteins involved in Moco biosynthesis in bacteria is regulated by the transcriptional regulator for fumarate and nitrate reduction, FNR [78,79]. The activity of FNR itself is directly dependent on the availability of Fe-S clusters under anaerobic conditions; consequently, Moco is not synthesized and molybdoenzymes are not expressed when Fe-S clusters are not assembled (Figure 4).

\subsection{The Involvement of Radical SAM Chemistry for Moco Biosynthesis}

The first step of Moco biosynthesis, the conversion of GTP into cPMP, directly depends on the assembly of [4Fe-4S] clusters, which proceeds through a complex rearrangement reaction, where C8 of guanine is being inserted between $\mathrm{C}^{\prime}$ and $\mathrm{C}^{\prime}$ ' of ribose [60]. During this reaction, MoaA plays a key role. MoaA is the only protein that binds Fe-S clusters in the pathway of Moco biosynthesis and was grouped into the superfamily of radical/SAM enzymes. In general, the mechanism of radical SAM 
chemistry involves the $[4 \mathrm{Fe}-4 \mathrm{~S}]^{2+}$ cluster bound to the $\mathrm{C}-\mathrm{X}_{3}-\mathrm{C}-\mathrm{X}_{2}-\mathrm{C}$ motif located at the $\mathrm{N}$-terminus of radical SAM superfamily enzymes (Figure 6).

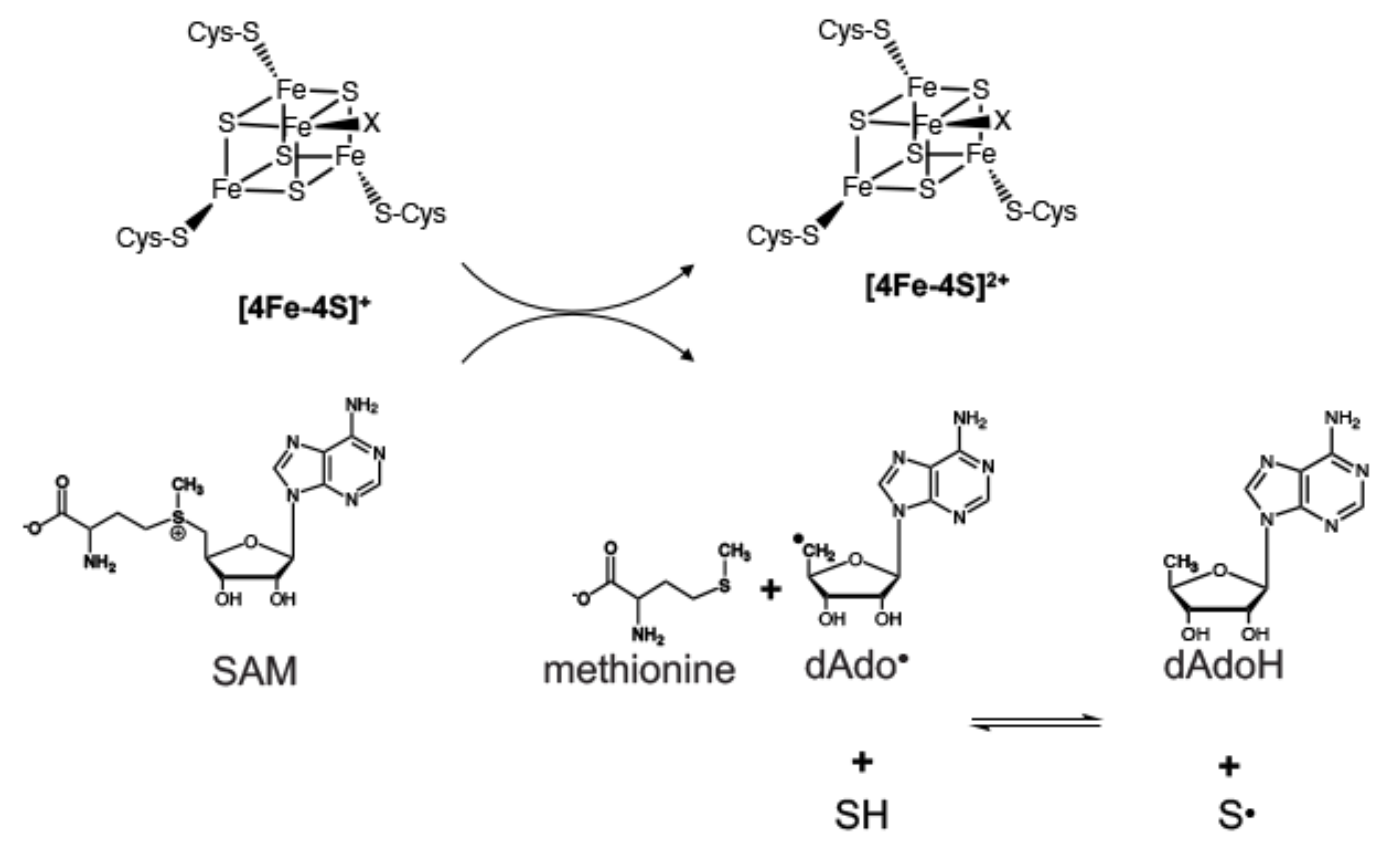

Figure 6. A general scheme for the mechanism of radical-SAM enzymes. The [4Fe-4S] that is bound to the conserved $\mathrm{C}-\mathrm{X}_{3}-\mathrm{C}-\mathrm{X}_{2}-\mathrm{C}$ motif provides the electron required for the reductive cleavage of SAM. In this reaction, methionine and the adenosyl radical (dAdo.) is generated. The formed dAdo then abstracts a hydrogen atom from the substrate (SH), and a substrate radical (S.) and dAdoH are formed.

The cluster is reduced by one electron to the catalytically-active state and coordinates the substrate $5^{\prime}$ S-adenosyl-methionine (SAM). In the reduced $[4 \mathrm{Fe}-4 \mathrm{~S}]^{+}$state, the cluster transfers an electron to the sulfonium sulfur of SAM, thereby promoting homolytic S-C bond cleavage to generate the $5^{\prime}$-deoxyadenosyl radical intermediate (dAdo.) and methionine. The dAdo intermediate then abstracts a hydrogen atom from the substrate. The $5^{\prime}$-deoxyadenosine $(\mathrm{dAdoH})$ is formed, and the resulting product radical intermediate may either be the end product or can undergo further transformations (Figure 6).

In the first step of Moco biosynthesis, MoaA and MoaC catalyze the conversion of 5'GTP into cyclic pyranopterin monophosphate (cPMP). MoaA is a member of the radical SAM superfamily and binds the characteristic [4Fe-4S] cluster at the $\mathrm{N}$-terminus and an additional [4Fe-4S] at the C-terminus. For Fe-S cluster insertion into MoaA, recent studies showed that both ErpA and IscA can provide Fe-S clusters to MoaA. Since $\Delta e r p A / \Delta i s c A$ double mutant strains were revealed to be completely devoid of Moco, it was concluded that SufA is unable to substitute the roles of both A-type carrier proteins for Moco biosynthesis (unpublished results).

The mechanism of cPMP formation was first investigated using isotope labeling experiments, which indicated that the C-8 atom of the guanine base of GTP is inserted between the $\mathrm{C}^{\prime}$ and $\mathrm{C}^{\prime}{ }^{\prime}$ atoms of the ribose moiety.

Recent studies showed that MoaA catalyzes the conversion of GTP into a $3^{\prime}, 8$-cyclo-7,8dihydroguanosine $5^{\prime}$-triphosphate $\left(3^{\prime}, 8-\mathrm{cH}_{2} \mathrm{GTP}\right)$ intermediate (Figure 7). The conversion of GTP into $3^{\prime}, 8-\mathrm{CH}_{2} \mathrm{GTP}$ by MoaA proceeds through a radical formation at $\mathrm{C}^{\prime}$ by the abstraction of the $\mathrm{H}-3^{\prime}$ atom of GTP by $5^{\prime}$-dAdo $[15,80]$. The free radical generated at the $\mathrm{C}^{\prime}$ of the ribose has been revealed by isotope labeling studies $[15,80]$, where a deuterium atom at the $3^{\prime}$-position was shown to be transferred to $\mathrm{dAdoH}$. The resulting $\mathrm{C}^{\prime}$ centered radical attacks $\mathrm{C} 8$ to form the aminyl radical intermediate, which is then reduced by transfer of an electron and a proton to form $3^{\prime}, 8-\mathrm{cH}_{2} \mathrm{GTP}$. Therefore, MoaA catalyzes the $\mathrm{C}-\mathrm{C}$ bond formation between the GTP $\mathrm{C}^{\prime}$ and the $\mathrm{C} 8$ of the guanine, resulting in the 
$3^{\prime}, 8-\mathrm{cH}_{2} \mathrm{GTP}$ intermediate as the end product of the MoaA catalyzed reaction. The conversion of $3^{\prime}, 8-\mathrm{cH}_{2} \mathrm{GTP}$ to cPMP is catalyzed by MoaC in the next step of the reaction [15]. It has been proposed that two loops in MoaC provide conformational flexibility of the enzyme that facilitates a general acid/base-catalyzed mechanism for the formation of the pyranopterin structure that is coupled to the cyclic phosphate ring formation (Figure 7). This step catalyzed by MoaC involves the irreversible cleavage of the pyrophosphate group that has been proposed to provide the thermodynamic driving force for the overall reaction.

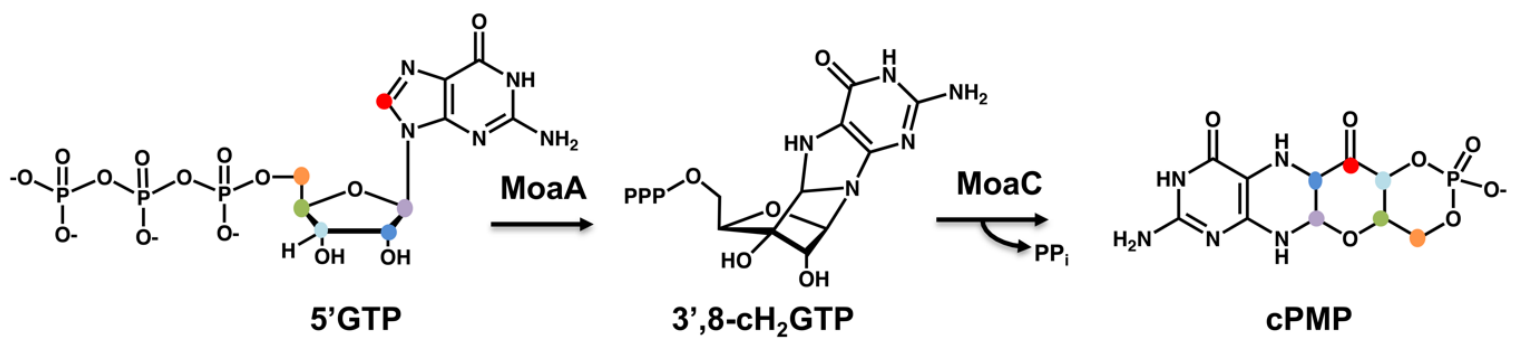

Figure 7. The conversion of 5'GTP to CPMP involving the functions of MoaA and MoaC. The colors on $5^{\prime} \mathrm{GTP}$ and CPMP indicate the source of the carbon and nitrogen atoms in cPMP as determined by isotope labeling studies. The reaction involves the formation of $3^{\prime}, 8-\mathrm{cH} 2 \mathrm{GTP}$ as the product of MoaA and the substrate for MoaC.

\subsection{Sulfur Mobilization Involves Sharing of Protein Functions in Prokaryotes}

In the next step of Moco biosynthesis, cPMP is converted to MPT in a reaction catalyzed by MPT synthase [54,61-64]. In this reaction, two sulfur atoms are inserted into the C2' position of cPMP and the $\mathrm{C}^{\prime}$ position of the formed hemisulfurated intermediate [65]. In bacteria, MPT synthase is composed as a $(\alpha \beta)_{2}$ heterotetramer of two central MoaE subunits, each binding one MoaD subunit (Figure 4) [66]. The sulfur atoms required for this reaction are bound as thiocarboxylate groups at the C-terminus of each MoaD subunit $[67,68]$. After the sulfur transfer reaction, the thiocarboxylate group is regenerated on each MoaD subunit. This reaction is catalyzed by MoeB under ATP consumption $[81,82]$. In the course of the reaction, MoaD dissociates from MoaE and reassociates with MoeB in a $(\alpha \beta)_{2}$ heterotetramer. In the first step, an acyl-adenylate group is formed at the C-terminus of MoaD $[81,83,84]$. In a second step, sulfur is directly transferred from a sulfur transferase to the activated MoaD-AMP C-terminus, and the MoaD thiocarboxylate (MoaD-COSH) is rebuilt. MoaD-COSH then dissociates from the (MoeB-MoaD) 2 complex and MoaD reassociates with MoaE [84,85]. The proteins IscS and TusA are proposed to be involved in the sulfur transfer reaction for the formation of the MoaD thiocarboxylate group in E. coli (Figure 4) [86,87]. It has been proposed that IscS first forms a persulfide group on TusA that is then reductively cleaved and transferred to MoaD by attacking the MoaD-AMP bond $[88,89]$.

After MPT formation, the dithiolene group of MPT serves as the backbone for molybdenum ligation. This step is catalyzed by MogA and MoeA under ATP consumption by the formation of an MPT-AMP intermediate catalyzed by MogA. After molybdate insertion into MPT-AMP in a MoeA-dependent reaction, the resulting tri-oxo Mo-MPT is either inserted into enzymes of the SO family or is further modified by nucleotide (GMP or CMP) addition, forming the MCD or bis-MGD cofactors, respectively.

\subsection{The Insertion of Different Cofactors into Molybdoenzymes in Bacteria}

Molybdoenzymes are generally composed of different subunits harboring additional prosthetic groups, such as cytochromes, the Fe-S cluster, or FAD/FMN that are involved in intramolecular electron transfer reactions (Figure 4) [50]. The molybdenum atom thereby exists in the oxidation states VI, V, or IV under physiological conditions and acts as a transducer between 2 electron transfer and 1 electron transfer processes often coupled to proton transfer. 
In general, Moco is deeply buried within the enzyme that is accessible via a substrate-binding funnel leading to the molybdenum atom [90]. It has been suggested that Moco insertion is accomplished by molecular chaperones that induce the final folding of the enzymes after Moco insertion [91]. The insertion of the different forms of Moco has been best studied in bacteria. In E. coli, many molybdoenzymes are located in the periplasm and require the Tat system for their translocation. The transport of enzymes occurs in the folded state after the insertion of the Moco and Fe-S clusters or other cofactors. This translocation presents a "quality control" step accomplished by the chaperones as Moco insertases and ensures that only the matured enzymes that contain Moco are translocated. After subunit assembly, Moco is inserted, final folding of the enzyme is accomplished, the enzyme is directed to the Tat-translocon and finally exported to the periplasm.

For Fe-S cluster insertion into enzymes, several A-type carriers have been identified that facilitate this process [40]. These proteins, which are SufA, IscA, or ErpA in E. coli, carry and insert the Fe-S clusters to designated target proteins. Previous reports suggested that ErpA is essential for the formation of an active formate-nitrate reductase complex in E. coli [92]. It was shown that E. coli erpA mutant strains were devoid of formate dehydrogenase and nitrate reductase activities. In these studies, IscA was able to partially complement the erp $A$ mutant, showing that these proteins might have overlapping roles, but ErpA seems to be the more specific enzyme for nitrate reductase and formate reductase maturation [92]. However, the overlapping effects of Fe-S cluster assembly and biosynthesis and insertion of Moco were not accounted for in this study. Since MoaA contains Fe-S clusters, the effect of the $\operatorname{erp} A$ mutant might have already been a decrease in MoaA activity, leading to a lack of Moco in the cell. Recent studies revealed that NarG is not expressed in erpA mutant strains and that inactive FNR precludes the expression of the narGHJI operon (unpublished results). Additionally, it was shown that ErpA and IscA are involved in Fe-S cluster insertion into MoaA (unpublished results), so that the inactivity of nitrate reductase and formate dehydrogenase in erp $A$ mutant strains is likely rather based on the lack of Moco. It still remains possible that, in addition, ErpA and IscA are involved in Fe-S cluster insertion into these molybdoenzymes. However, based on the lack of expression of the FNR-regulated operons, the involvement of these proteins cannot be analyzed. Thus, it is difficult to dissect the combined effects of Moco biosynthesis and Fe-S cluster insertion for molybdoenzyme maturation.

\section{Compartmentalization of Fe-S Cluster and Moco Biosynthesis in Eukaryotes: The Role of Mitochondria}

\subsection{Mitochondrial Fe-S Cluster Biosynthesis in Eukaryotes}

In eukaryotes, the main Fe-S cluster assembly is localized in the mitochondria, which were derived from bacteria by endosymbiosis. The key component for Fe-S cluster biosynthesis in mitochondria is the L-cysteine desulfurase NFS1, which forms the central dimer (Figure 8).

The enzyme serves as the general sulfur donor for cellular Fe-S cluster synthesis, also for cytosolic Fe-S clusters. At the NFS1 dimer interface, a dimer of ISD11 is bound that stabilizes NFS1 [93-95]. While ISD11 is conserved in eukaryotes [96], a prokaryotic homolog of ISD11 is not known [93]. ISD11 belongs to the large family of LYRM proteins that fold into a triple-helical bundle [97]. ISD11 contributes to the interaction with the acyl carrier protein ACP1 [93]. While ACP1 is not needed for efficient synthesis of the [2Fe-2S] cluster on ISCU2, the ISD11-ACP1 sub-complex was proposed to regulate Fe-S cluster assembly by linking the energy load of the cells to the Fe-S cluster assembly complex [98]. Each monomer of the NFS1 dimer binds frataxin (FXN), ISCU2, and FDX2 at the two opposite ends. For the conversion of the persulfide sulfur $\left(\mathrm{S}^{0}\right)$ to sulfide $\left(\mathrm{S}^{2-}\right)$, electrons are required, which are provided by FDX2 [99-102]. First, a [2Fe-2S] cluster is formed on ISCU2, by combining Fe ${ }^{2+}$ entry from a still unresolved iron donor and $S^{2-}$ provided by NFS1. The role of FXN in this process is still under debate.

The next step in mitochondrial Fe-S protein biogenesis involves the dissociation of the [2Fe-2S] cluster from ISCU2, its trafficking to the monothiol glutaredoxin GLRX5 as an intermediate Fe-S cluster binding partner, and the specific insertion into target proteins (Figure 8) [103-105]. This reaction 
requires the roles of the dedicated chaperone system of the Hsp40-Hsp70 (DnaJ-DnaK) class [106,107]. For cluster transfer, the DnaJ co-chaperone HSC20 binds to a hydrophobic motif in ISCU2 [97,108,109]. The HSC20-ISCU2 complex then recruits the Hsp70 chaperone HSPA9. In the next step, the cluster is transferred to GLRX5. For [2Fe-2S] cluster transfer to target proteins, no further proteins are required [110]. However, since GLRX5 is not essential, the protein function can be bypassed by direct transfer of [2Fe-2S] from ISCU2.

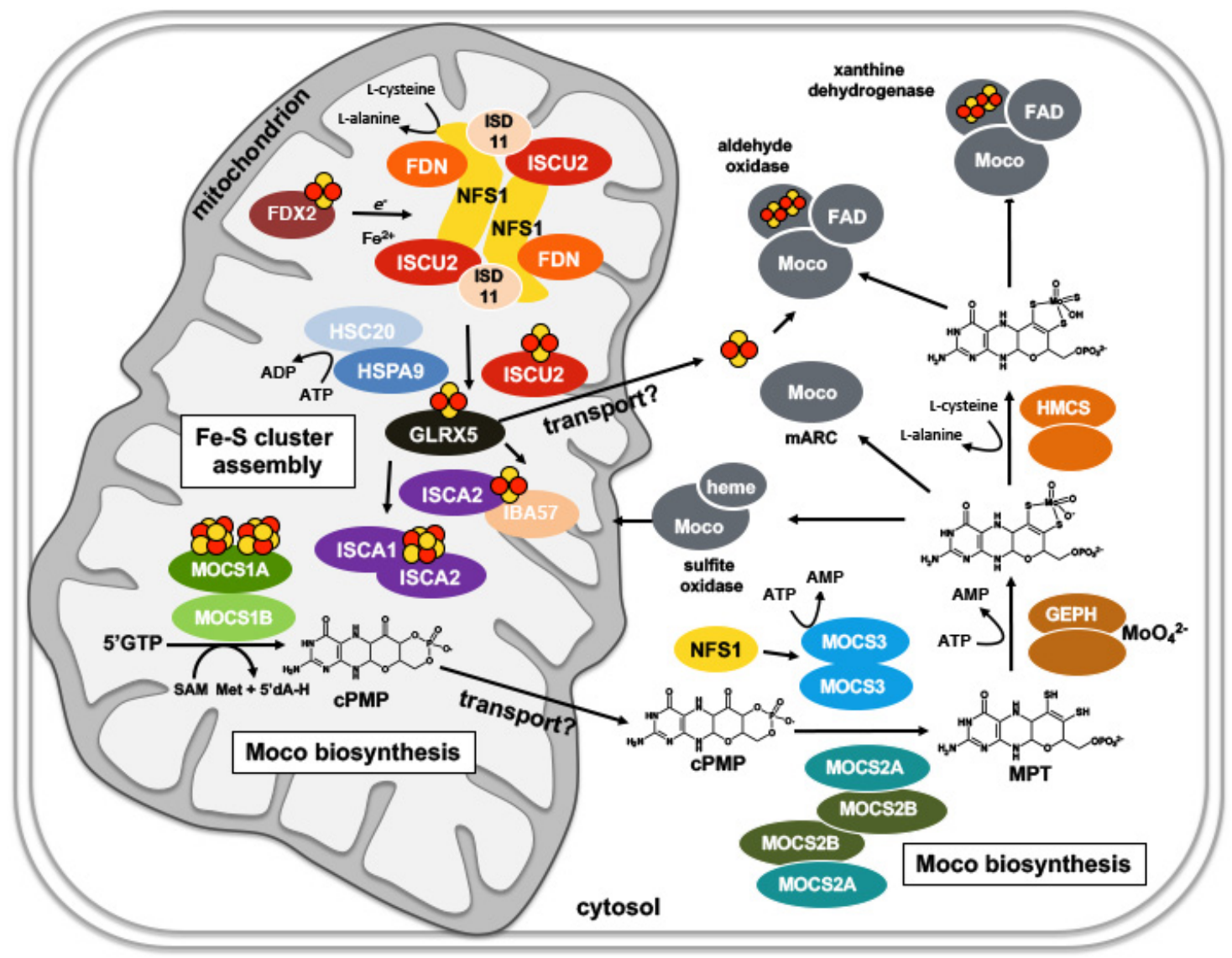

Figure 8. The different compartments for the biosynthesis of Moco in humans and the link to Fe-S cluster assembly in mitochondria. The first step of Moco biosynthesis, the conversion of 5'GTP to cPMP catalyzed by MOCS1A and MOCS1B, is localized in mitochondria. This is also the main compartment for Fe-S cluster biosynthesis in eukaryotes. Fe-S clusters assemble on the scaffold protein ISCU2, which receives the sulfur from the L-cysteine desulfurase complex NFS1/ISD11. Frataxin (FDN) interacts with the NFS1/Isd11-ISCU2 complex to form the quaternary complex. Ferredoxin (FDX2) delivers the electrons for the process. Assembly and release of the clusters from ISCU2 are facilitated by the chaperones HSC20/HSPA9. The carrier proteins GLRX5, ISCA2, and/or IBA57 deliver the Fe-S clusters to target proteins, like MOCS1A in Moco biosynthesis. Synthesized cPMP by MOCS1A/B needs to be transferred to the cytosol, where all further modification steps of Moco are catalyzed. These steps involve the conversion of CPMP to MPT by MOCS2A/MOCS2B (which are activated by MOCS3), the insertion of molybdate by GEPHYRIN (GEPH), and the insertion of Mo-MPT either to the mARC protein (localized at the outer mitochondrial membrane) or to sulfite oxidase (before its translocation to the mitochondrial intermembrane space). For aldehyde oxidase and xanthine dehydrogenase, the formation of the equatorial sulfido-ligand is transferred by HMCS. Dual localization of NFS1 both in mitochondria and the cytosol is predicted. Cytosolic NFS1 acts as a sulfur donor for MOCS3.

The assembly and insertion of [4Fe-4S] clusters additionally require the A-type ISC proteins ISCA1-ISCA2 and IBA57 (Figure 8) [111-114]. How these proteins mechanistically assist the fusion of the $[2 \mathrm{Fe}-2 \mathrm{~S}]$ into a [4Fe-4S] cluster is a complex process involving the transfer of [2Fe-2S] clusters from 
GLRX5 to ISCA1-ISCA2 and the assembly of a [4Fe-4S] cluster on the ISCA1-ISCA2 complex [115-117]. IBA57 is not required in this step. IBA57 was shown to form a [2Fe-2S] cluster-mediated complex specifically with ISCA2, involving GLRX5 [111,118,119]. Mitochondrial [4Fe-4S] cluster biosynthesis is a dynamic system, also involving Nfu1, Ind1 and BolA3 in some cases (recently reviewed in Reference [120]). The Fe-S cluster insertion for the human MoaA homologue MOCS1A (see below) has not been investigated so far.

\subsection{Cytosolic Fe-S Cluster Assembly: The CIA Machinery}

For cytosolic Fe-S cluster assembly, the mitochondrial ISC system has been proposed to be essential [121,122]. Studies by several groups have shown that the mitochondrial ISC machinery generates a sulfur-containing factor " $\mathrm{X}-\mathrm{S}$ " that is exported to the cytosol via the mitochondrial $\mathrm{ABC}$ transporter $\mathrm{ABCB} 7$ and is used for cytosolic Fe-S cluster assembly by the CIA machinery (Figure 9) [12,123-125]. However, models also exist that propose that cytosolic versions of NFS1, ISCU, and FDN are involved in cytosolic Fe-S cluster formation [120]. The CIA machinery is composed of up to 13 known proteins that assemble both cytosolic and nuclear Fe-S proteins. Initially, a [4Fe-4S] cluster is assembled on the CIA scaffold complex formed between CFD1-NBP35 (Figure 9) [125,126]. The initial cluster synthesis on CFD1-NBP35 further requires the electron transfer chain composed of the flavin-dependent oxidoreductase NDOR1 and CIAPIN1, however, the precise role of the electron-transfer for cluster synthesis is not completely understood yet $[127,128]$. The insertion of the two Fe-S clusters of CIAPIN1 additionally requires the cytosolic monothiol glutaredoxin reductase GLRX3 [129-131]. GLRX3 binds a bridging [2Fe-2S] cluster with BOLA2 which is further transferred to CIAPIN1 (Figure 9) [130,132]. CIAPIN1 can coordinate a pair of [2Fe-2S] clusters or a [2Fe-2S] cluster and a [4Fe-4S] cluster $[115,128,133,134]$. While the BOLA2-GLRX3 complex is able to transfer [2Fe-2S] clusters to CIAPIN1, the formation of the [4Fe-4S] cluster in CIAPIN1 is still fully undefined.

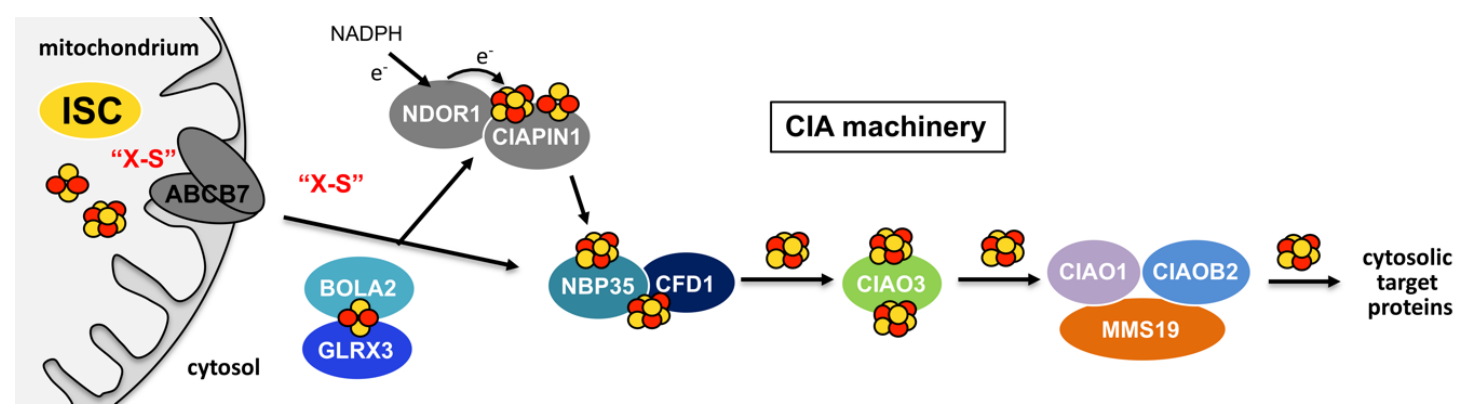

Figure 9. Model of the cytosolic Fe-S cluster assembly (CIA) in humans. Assembly of cytosolic Fe-S clusters starts in mitochondria with components of the early ISC machinery synthesizing a sulfur-containing precursor (X-S) that is subsequently exported to the cytosol by the ABC transporter ABCB7. The CIA machinery involves [4Fe-4S] cluster assembly by the CFD1-NBP35 complex serving as a cluster scaffold. This reaction requires electron input from the flavin-oxidoreductase NDOR1 and the Fe-S protein CIAPIN1. The complex of GLRX3-BOLA2 facilitates [2Fe-2S] cluster insertion into CIAPIN1. In the next step, the CFD1-NBP35-bound [4Fe-4S] cluster is released and transferred to the majority of target Fe-S apoproteins with the help of CIAO3. Fe-S cluster targeting to individual apoproteins is achieved by CIAO1, CIAO2B, and MMS19.

The next step of cytosolic Fe-S assembly involves the trafficking of the [4Fe-4S] cluster from the CFD1-NBP35 complex to CIAO3 and then to the CIA targeting complex (CTC) which is composed of CIAO1, CIAO2B, and MMS19 $[135,136]$. From this complex, which can be formed with different protein components, the cluster is transferred directly to target proteins (Figure 9). The specific interaction with the target proteins is mediated by the CTC proteins. 


\subsection{The Formation of cPMP Is Localized in Mitochondria}

The conversion of $5^{\prime}$ GTP to cPMP is localized in mitochondria in humans in a reaction that is catalyzed by MOCS1A and MOCS1B [137]. As explained above, this compartment is also the main compartment for the synthesis of Fe-S clusters (Figure 8). Since MOCS1A requires two [4Fe-4S] clusters for activity, it remains speculative that linking that first step of Moco biosynthesis to mitochondrial Fe-S cluster assembly provided a mechanistic advantage [138]. Since MOCS1A and MOCS1B are highly homologous to their bacterial counterparts, MoaA and MoaC, respectively, the conversion of $5^{\prime}$ GTP to CPMP is catalyzed by the same mechanism and is therefore not described in detail again (Figure 7). After cPMP formation, the molecule has to be transported to the cytosol, where all further steps of Moco biosynthesis are catalyzed. For plants, it has been suggested that the export of cPMP involves the transporter protein Atm3 [139]. The human counterpart to Atm3 is ABCB7 (Figure 9). Surprisingly, Atm3, like ABCB7 has initially been suggested to transport the "X-S" species essential for cytosolic Fe-S cluster assembly. The precise role of Atm3 is consequently still unknown and the defects in molybdoenzyme activities in Atm3 mutants might also be explained by an overlapping defect in Fe-S cluster assembly. Future studies are necessary to further explore the export of cPMP from mitochondria to the cytosol.

\subsection{Moco Is Formed in the Cytosol}

After its transport to the cytosol, cPMP is converted to MPT in the reaction catalyzed by MPT synthase. In humans, MPT synthase is formed by MOCS2A and MOCS2B, the homologues of MoaD and MoeB, respectively (Figure 10). Both the human and bacterial MPT synthases catalyze a similar reaction that is explained in detail for the bacterial counterparts above (Figure 4) [68].

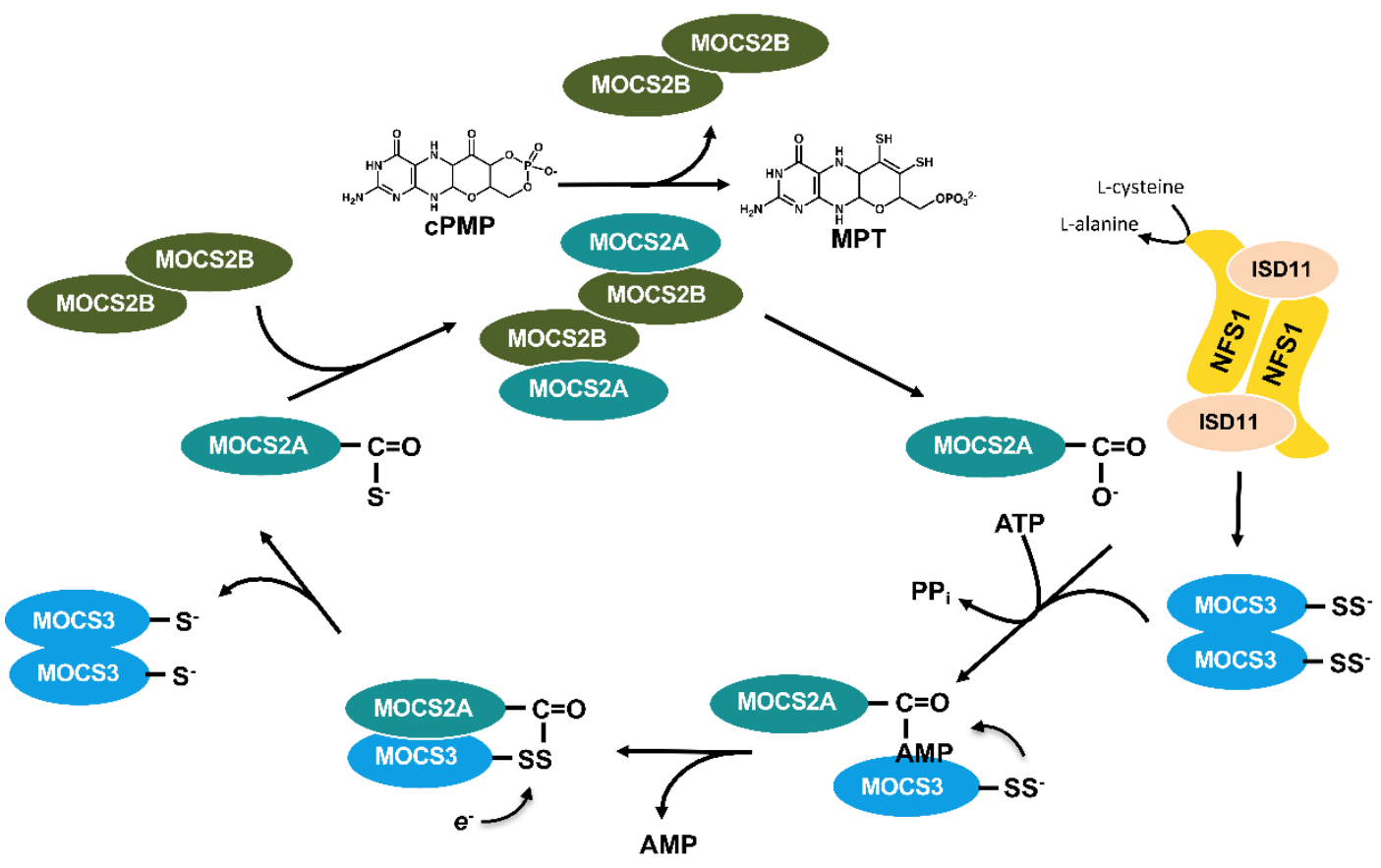

Figure 10. Regeneration of the thiocarboxylate group on MOCS2A. Conversion of cPMP to MPT requires the transfer of two sulfur, a reaction catalyzed by MPT synthase. The formation of the MOCS2A thiocarboxylate group is catalyzed after the formation of the (MOCS2A/MOCS3) 2 complex in humans. First, MOCS2A-AMP is formed under ATP consumption. MOCS3 receives the sulfur from NFS1, and a persulfide group is formed at the C-terminal domain of MOCS3. This sulfur is then transferred to MOCS2A with the formation of a perthiocarboxylate group as the intermediate. After reductive cleavage, the thiocarboxylate group on MOCS2A is formed and MOCS2A-SH reassociates with MOCS2B. 
After the MPT synthase reaction, the C-terminal carboxylate group on MOCS2A is regenerated by MOCS3 (Figure 10) [140]. MOCS3 contains an N-terminal domain that is homologous to the E. coli MoeB protein and a C-terminal domain that shares homologies to sulfur transferases (rhodaneses). First, the N-terminal domain of MOCS3 activates the C-terminus of MOCS2A under ATP consumption (Figure 10). In the second part of the reaction, sulfur is transferred from the C-terminal rhodanese-like domain of MOSC3 to the formed MOCS2A-AMP [141,142]. This reaction differs from the reaction described for the E. coli proteins, since the MOCS3 protein itself catalyzes both the adenylation and the sulfur transfer reaction. The persulfide group on MOCS3 has been suggested to be formed by the L-cysteine desulfurase NFS1 in the cytosol $[143,144]$. It has been proposed that small amounts of NFS1 in the cytosol are sufficient for supplying the sulfur for MPT formation [143]. Since for the CIA machinery cytosolic NFS1 might not be required, it remains possible that the role of NFS1 in the cytosol is restricted to Moco biosynthesis. Further studies are necessary to confirm this.

After the MPT formation, molybdate ion is ligated to the dithiolene group of MPT. GEPHYRIN is the homolog of the bacterial MogA and MoeA proteins (Figure 8) [145]. GEPHYRIN is a two-domain protein with one domain being homologous to MogA and the other domain being homologous to MoeA [146].

The chemistry of molybdenum insertion has been studied in detail for the plant counterpart of GEPHYRIN, named CNX1. The AMP-part of MPT-AMP functions as an anchor on the E-domain while the dithiolene moiety of MPT-AMP points to a separate pocket on the E-domain where molybdate is bound and waits to be inserted. Finally, the pyrophosphate bond between AMP and MPT is hydrolyzed and the newly-formed Moco is released [147].

After the completion of Moco, the cofactor can be directly inserted into the molybdoenzymes sulfite oxidase or mARC which belong to the SO family of molybdoenzymes (Figure 8) [148]. For the two enzymes of the XO family, xanthine dehydrogenase and aldehyde oxidase, Moco is further modified by the formation of an equatorial sulfido-group $[149,150]$. This reaction is catalyzed by a Moco sulfurase, named HMCS (human molybdenum cofactor sulfurase) before the insertion of the cofactor into molybdoenzymes (Figure 8). HMCS is a homodimeric two-domain protein with an N-terminal domain sharing homologies to the bacterial L-cysteine desulfurases IscS [151] and a C-terminal domain that binds Moco. The Moco-sulfido group is directly formed on Mo-MPT bound to the C-terminal domain by transfer of a persulfide group from the N-terminal domain [152,153]. After sulfuration, Moco is then inserted into the target enzymes xanthine dehydrogenase and aldehyde oxidase (Figure 8) [152,153]. So far, it is not known which enzymes of the CIA machinery insert the two [2Fe-2S] clusters into xanthine dehydrogenase or aldehyde oxidase.

\section{Conclusions}

In this review, we highlighted the link between the biosynthesis and maturation of molybdoenzymes and the biosynthesis and distribution of Fe-S clusters. Several levels of this link were identified: (a) the synthesis of the first intermediate in Moco biosynthesis requires a radical/SAM-dependent protein; (b) the sulfurtransferase for the dithiolene group in Moco is shared with the synthesis of Fe-S clusters; (c) the modification of the active site with a sulfur atom additionally involves an L-cysteine desulfurase, and (d) most molybdoenzymes require Fe-S clusters as additional redox-active cofactors. While the general pathways of the biosynthesis/assembly of Moco and Fe-S clusters have been studied in detail, numerous open questions still remain. One of the most intriguing questions in Fe-S cluster assembly is the source of the iron atom in the cluster. In particular, iron has to be provided in the correct oxidation state for biological processes. Further, after the biosynthesis of the complex cofactors like Fe-S clusters and Moco, intricate mechanisms have to control distribution, trafficking, and insertion of these cofactors into their specific target proteins. The transfer mechanisms involve cofactor-binding chaperones, as most of these prosthetic groups are extremely fragile and oxygen-sensitive. The specificity of the cluster transfer process into target proteins, their recognition, and the hierarchy in which metal-center insertion for Fe-S clusters and Moco occurs, is still largely 
unresolved. Also, the compound "X-S" that is delivered by the mitochondrial Fe-S cluster machinery to the CIA machinery is still unknown.

For humans, the molybdoenzyme sulfite oxidase is most crucial for survival and it is located in the mitochondrial intermembrane space. A lack of sulfite oxidase activity usually results in death in early childhood. The dependency on Fe-S clusters for the biosynthesis of Moco directly links Fe-S cluster related diseases to the severe outcome of sulfite oxidase deficiency. The link of Fe-S cluster related diseases to Moco deficiency needs to be investigated in future studies.

Author Contributions: Conceptualization, R.R.M. and S.L.; writing—original draft preparation, R.R.M. and S.L.; writing-review and editing, R.R.M., T.W.H., A.Z., M.A.H. and S.L.; visualization, S.L.; supervision, R.R.M. and S.L.; project administration, R.R.M. and S.L.; funding acquisition, R.R.M. and S.L. All authors have read and agreed to the published version of the manuscript.

Funding: The research was supported by continuous individual grants from the Deutsche Forschungsgemeinschaft (DFG, German Research Foundation) (LE1171/15-2, LE1171/11-2 to S.L. and ME1266/31-1 to R.R.M.) including funding by the DFG Priority Programme SPP1927 'FeS for Life' and by the DFG Research Training Group GRK 2223/1 'PROCOMPAS'.

Acknowledgments: The authors thank all current and former members of their research groups in addition to collaboration partners who were involved in the work over the past years.

Conflicts of Interest: The authors declare no conflict of interest.

\section{References}

1. Andreini, C.; Bertini, I.; Cavallaro, G.; Holliday, G.L.; Thornton, J.M. Metal ions in biological catalysis: From enzyme databases to general principles. JBIC J. Boil. Inorg. Chem. 2008, 13, 1205-1218. [CrossRef] [PubMed]

2. Beinert, H.; Holm, R.H.; Munck, E. Iron-Sulfur Clusters: Nature's Modular, Multipurpose Structures. Science 1997, 277, 653-659. [CrossRef] [PubMed]

3. Stehling, O.; Wilbrecht, C.; Lill, R. Mitochondrial iron-sulfur protein biogenesis and human disease. Biochimie 2014, 100, 61-77. [CrossRef]

4. Roche, B.; Aussel, L.; Ezraty, B.; Mandin, P.; Py, B.; Barras, F. Iron/sulfur proteins biogenesis in prokaryotes: Formation, regulation and diversity. Biochim. Biophys. 2013, 1827, 455-469. [CrossRef]

5. Arnon, D.I.; Whatley, F.R.; Allen, M.B. Triphosphopyridine Nucleotide as a Catalyst of Photosynthetic Phosphorylation. Nature 1957, 180, 182-185. [CrossRef] [PubMed]

6. Mortenson, L.E.; Valentine, R.C.; Carnahan, J.E. An electron transport factor from Clostridium pasteurianum. Biochem. Biophys. Res. Commun. 1962, 7, 448-452. [CrossRef]

7. Beinert, H.; Sands, R.H. Studies on succinic and DPNH dehydrogenase preparations by paramagnetic resonance (EPR) spectroscopy. Biochem. Biophys. Res. Commun. 1960, 3, 41-46. [CrossRef]

8. Malkin, R.; Rabinowitz, J.C. The reconstitution of clostridial ferredoxin. Biochem. Biophys. Res. Commun. 1966, 23, 822-827. [CrossRef]

9. Wachtershäuser, G. Groundworks for an evolutionary biochemistry: The iron-sulphur world. Prog. Biophys. Mol. Boil. 1992, 58, 85-201. [CrossRef]

10. Lill, R.; Mühlenhoff, U. Iron-Sulfur Protein Biogenesis in Eukaryotes: Components and Mechanisms. Annu. Rev. Cell Dev. Boil. 2006, 22, 457-486. [CrossRef]

11. Zheng, L.; Cash, V.L.; Flint, D.H.; Dean, D.R. Assembly of iron-sulfur clusters. Identification of an iscSUA-hscBA-fdx gene cluster from Azotobacter vinelandii. J. Biol. Chem. 1998, 273, 13264-13272. [CrossRef]

12. Kispal, G.; Csere, P.; Prohl, C.; Lill, R. The mitochondrial proteins Atm1p and Nfs1p are essential for biogenesis of cytosolic Fe/S proteins. EMBO J. 1999, 18, 3981-3989. [CrossRef]

13. Sofia, H.J.; Chen, G.; Hetzler, B.G.; Reyes-Spindola, J.F.; Miller, N.E. Radical SAM, a novel protein superfamily linking unresolved steps in familiar biosynthetic pathways with radical mechanisms: Functional characterization using new analysis and information visualization methods. Nucleic Acids Res. 2001, 29, 1097-1106. [CrossRef]

14. Broderick, J.B.; Duffus, B.R.; Duschene, K.S.; Shepard, E.M. Radical S-Adenosylmethionine Enzymes. Chem. Rev. 2014, 114, 4229-4317. [CrossRef] 
15. Hover, B.M.; Loksztejn, A.; Ribeiro, A.A.; Yokoyama, K. Identification of a Cyclic Nucleotide as a Cryptic Intermediate in Molybdenum Cofactor Biosynthesis. J. Am. Chem. Soc. 2013, 135, 7019-7032. [CrossRef]

16. Pang, H.; Yokoyama, K. Lessons from the Studies of a C-C Bond Forming Radical SAM Enzyme in Molybdenum Cofactor Biosynthesis. Methods Enzym. 2018, 606, 485-522.

17. Xu, X.M.; Moller, S. Iron-Sulfur Clusters: Biogenesis, Molecular Mechanisms, and Their Functional Significance. Antioxidants Redox Signal. 2011, 15, 271-307. [CrossRef]

18. Glasner, J.D.; Yang, C.-H.; Reverchon, S.; Hugouvieux-Cotte-Pattat, N.; Condemine, G.; Bohin, J.-P.; Van Gijsegem, F.; Yang, S.; Franza, T.; Expert, D.; et al. Genome Sequence of the Plant-Pathogenic Bacterium Dickeya dadantii 3937. J. Bacteriol. 2011, 193, 2076-2077. [CrossRef] [PubMed]

19. Tsaousis, A.D. On the Origin of Iron/Sulfur Cluster Biosynthesis in Eukaryotes. Front. Microbiol. 2019, 10, 2478. [CrossRef] [PubMed]

20. Beinert, H. Iron-sulfur proteins: Ancient structures, still full of surprises. JBIC J. Boil. Inorg. Chem. 2000, 5, 2-15. [CrossRef] [PubMed]

21. Blanc, B.; Gerez, C.; De Choudens, S.O. Assembly of Fe/S proteins in bacterial systems: Biochemistry of the bacterial ISC system. Biochim. Biophys. Acta 2015, 1853, 1436-1447. [CrossRef]

22. Bühning, M.; Valleriani, A.; Leimkühler, S. The Role of SufS Is Restricted to Fe-S Cluster Biosynthesis in Escherichia coli. Biochemistry 2017, 56, 1987-2000. [CrossRef] [PubMed]

23. Hidese, R.; Mihara, H.; Esaki, N. Bacterial cysteine desulfurases: Versatile key players in biosynthetic pathways of sulfur-containing biofactors. Appl. Microbiol. Biotechnol. 2011, 91, 47-61. [CrossRef]

24. Outten, F.W.; Djaman, O.; Storz, G. A suf operon requirement for Fe-S cluster assembly during iron starvation in Escherichia coli. Mol. Microbiol. 2004, 52, 861-872. [CrossRef]

25. Urbina, H.D.; Silberg, J.J.; Hoff, K.G.; Vickery, L.E. Transfer of Sulfur from IscS to IscU during Fe/S Cluster Assembly. J. Boil. Chem. 2001, 276, 44521-44526. [CrossRef]

26. Shi, R.; Proteau, A.; Villarroya, M.M.; Moukadiri, I.; Zhang, L.; Trempe, J.-F.; Matte, A.; Armengod, M.E.; Cygler, M. Structural Basis for Fe-S Cluster Assembly and tRNA Thiolation Mediated by IscS Protein-Protein Interactions. PLoS Boil. 2010, 8, e1000354. [CrossRef]

27. Roche, B.; Huguenot, A.; Barras, F.; Py, B. The iron-binding CyaY and IscX proteins assist the ISC-catalyzed Fe-S biogenesis in Escherichia coli. Mol. Microbiol. 2015, 95, 605-623. [CrossRef]

28. Cupp-Vickery, J.R.; Urbina, H.; Vickery, L.E. Crystal structure of IscS, a cysteine desulfurase from Escherichia coli. J. Mol. Boil. 2003, 330, 1049-1059. [CrossRef]

29. Chandramouli, K.; Unciuleac, M.C.; Naik, S.; Dean, D.R.; Huynh, B.H.; Johnson, M.K. Formation and Properties of [4Fe-4S] Clusters on the IscU Scaffold Proteint. Biochemistry 2007, 46, 6804-6811. [CrossRef] [PubMed]

30. Kim, J.H.; Frederick, R.O.; Reinen, N.M.; Troupis, A.T.; Markley, J.L. [2Fe-2S]-Ferredoxin Binds Directly to Cysteine Desulfurase and Supplies an Electron for Iron-Sulfur Cluster Assembly but Is Displaced by the Scaffold Protein or Bacterial Frataxin. J. Am. Chem. Soc. 2013, 135, 8117-8120. [CrossRef]

31. Yan, R.; Konarev, P.V.; Iannuzzi, C.; Adinolfi, S.; Roche, B.; Kelly, G.; Simon, L.; Martin, S.R.; Py, B.; Barras, F.; et al. Ferredoxin Competes with Bacterial Frataxin in Binding to the Desulfurase IscS. J. Boil. Chem. 2013, 288, 24777-24787. [CrossRef] [PubMed]

32. Kim, J.H.; Tonelli, M.; Frederick, R.O.; Chow, D.C.; Markley, J.L. Specialized Hsp70 Chaperone (HscA) Binds Preferentially to the Disordered Form, whereas J-protein (HscB) Binds Preferentially to the Structured Form of the Iron-Sulfur Cluster Scaffold Protein (IscU). J. Boil. Chem. 2012, 287, 31406-31413. [CrossRef] [PubMed]

33. Iametti, S.; Barbiroli, A.; Bonomi, F. Functional implications of the interaction between HscB and IscU in the biosynthesis of FeS clusters. J. Boil. Inorg. Chem. 2015, 20, 1039-1048. [CrossRef]

34. Loiseau, L.; Ollagnier-De-Choudens, S.; Nachin, L.; Fontecave, M.; Barras, F. Biogenesis of Fe-S Cluster by the Bacterial Suf System: SufS and SufE form a new type of cysteine desulfurase. J. Boil. Chem. 2003, 278, 38352-38359. [CrossRef]

35. Perard, J.; Ollagnier-De-Choudens, S. Correction to: Iron-sulfur clusters biogenesis by the SUF machinery: Close to the molecular mechanism understanding. J. Boil. Inorg. Chem. 2018, 23, 581-596. [CrossRef]

36. Zheng, C.; Dos Santos, P.C. Metallocluster transactions: Dynamic protein interactions guide the biosynthesis of Fe-S clusters in bacteria. Biochem. Soc. Trans. 2018, 46, 1593-1603. [CrossRef]

37. Selbach, B.P.; Pradhan, P.K.; Dos Santos, P.C. Protected Sulfur Transfer Reactions by the Escherichia coli Suf System. Biochemistry 2013, 52, 4089-4096. [CrossRef] 
38. Black, K.A.; Dos Santos, P.C. Shared-intermediates in the biosynthesis of thio-cofactors: Mechanism and functions of cysteine desulfurases and sulfur acceptors. Biochim. Biophys. Acta 2015, 1853, 1470-1480. [CrossRef]

39. Tan, G.; Lu, J.; Bitoun, J.P.; Huang, H.; Ding, H. IscA/SufA paralogues are required for the [4Fe-4S] cluster assembly in enzymes of multiple physiological pathways in Escherichia coli under aerobic growth conditions. Biochem. J. 2009, 420, 463-472. [CrossRef]

40. Vinella, D.; Brochier-Armanet, C.; Loiseau, L.; Talla, E.; Barras, F. Iron-Sulfur (Fe/S) Protein Biogenesis: Phylogenomic and Genetic Studies of A-Type Carriers. PLoS Genet. 2009, 5, e1000497. [CrossRef]

41. Loiseau, L.; Gerez, C.; Bekker, M.; Choudens, S.O.-D.; Py, B.; Sanakis, Y.; De Mattos, J.T.; Fontecave, M.; Barras, F. ErpA, an iron-sulfur (Fe-S) protein of the A-type essential for respiratory metabolism in Escherichia coli. Proc. Natl. Acad. Sci. USA 2007, 104, 13626-13631. [CrossRef]

42. Angelini, S.; Gerez, C.; Ollagnier-de Choudens, S.; Sanakis, Y.; Fontecave, M.; Barras, F.; Py, B. NfuA, a new factor required for maturing $\mathrm{Fe} / \mathrm{S}$ proteins in Escherichia coli under oxidative stress and iron starvation conditions. J. Biol. Chem. 2008, 283, 14084-14091. [CrossRef] [PubMed]

43. Picciocchi, A.; Saguez, C.; Boussac, A.; Cassier-Chauvat, C.; Chauvat, F.; Cassier-Chauvat, C. CGFS-Type Monothiol Glutaredoxins from the Cyanobacterium Synechocystis PCC6803 and Other Evolutionary Distant Model Organisms Possess a Glutathione-Ligated [2Fe-2S] Cluster. Biochemistry 2007, 46, 15018-15026. [CrossRef] [PubMed]

44. Boutigny, S.; Saini, A.; Baidoo, E.E.; Yeung, N.; Keasling, J.D.; Butland, G. Physical and Functional Interactions of a Monothiol Glutaredoxin and an Iron Sulfur Cluster Carrier Protein with the Sulfur-donating Radical S-Adenosyl-L-methionine Enzyme MiaB. J. Boil. Chem. 2013, 288, 14200-14211. [CrossRef]

45. Boyd, J.M.; Lewis, J.A.; Escalante-Semerena, J.C.; Downs, D.M. Salmonella enterica Requires ApbC Function for Growth on Tricarballylate: Evidence of Functional Redundancy between ApbC and IscU. J. Bacteriol. 2008, 190, 4596-4602. [CrossRef] [PubMed]

46. Boyd, J.M.; Sondelski, J.L.; Downs, D.M. Bacterial ApbC protein has two biochemical activities that are required for in vivo function. J. Biol. Chem. 2009, 284, 110-118. [CrossRef]

47. Schwartz, C.J.; Giel, J.L.; Patschkowski, T.; Luther, C.; Ruzicka, F.J.; Beinert, H.; Kiley, P.J. IscR, an Fe-S cluster-containing transcription factor, represses expression of Escherichia coli genes encoding Fe-S cluster assembly proteins. Proc. Natl. Acad. Sci. USA 2001, 98, 14895-14900. [CrossRef]

48. Rajagopalan, K.V.; Johnson, J.L. The pterin molybdenum cofactors. J. Boil. Chem. 1992, 267, 10199-10202.

49. Rajagopalan, K.V. Biosynthesis of the molybdenum cofactor. In Escherichia coli and Salmonella. Cellular and Molecular Biology; Neidhardt, F.C., Ed.; ASM Press: Washington, DC, USA, 1996; pp. 674-679.

50. Hille, R.; Hall, J.; Basu, P. The Mononuclear Molybdenum Enzymes. Chem. Rev. 2014, 114, $3963-4038$. [CrossRef]

51. Leimkühler, S.; Wuebbens, M.M.; Rajagopalan, K. The history of the discovery of the molybdenum cofactor and novel aspects of its biosynthesis in bacteria. Coord. Chem. Rev. 2011, 255, 1129-1144. [CrossRef]

52. Mendel, R.; Leimkühler, S. The biosynthesis of the molybdenum cofactors. J. Boil. Inorg. Chem. 2015, 20, 337-347. [CrossRef] [PubMed]

53. Wuebbens, M.M.; Rajagopalan, K.V. Structural characterization of a molybdopterin precursor. J. Boil. Chem. 1993, 268, 13493-13498.

54. Pitterle, D.M.; Johnson, J.L.; Rajagopalan, K.V. In Vitro synthesis of molybdopterin from precursor Z using purified converting factor. Role of protein-bound sulfur in formation of the dithiolene. J. Boil. Chem. 1993, $268,13506-13509$.

55. Joshi, M.S.; Johnson, J.L.; Rajagopalan, K.V. Molybdenum cofactor biosynthesis in Escherichia coli mod and mog mutants. J. Bacteriol. 1996, 178, 4310-4312. [CrossRef]

56. Johnson, J.L.; Bastian, N.R.; Rajagopalan, K.V. Molybdopterin guanine dinucleotide: A modified form of molybdopterin identified in the molybdenum cofactor of dimethyl sulfoxide reductase from Rhodobacter sphaeroides forma specialis denitrificans. Proc. Natl. Acad. Sci. USA 1990, 87, 3190-3194. [CrossRef]

57. Meyer, O.; Rajagopalan, K.V. Molybdopterin in carbon monoxide oxidase from carboxydotrophic bacteria. J. Bacteriol. 1984, 157, 643-648. [CrossRef]

58. Neumann, M.; Mittelstadt, G.; Seduk, F.; Iobbi-Nivol, C.; Leimkuhler, S. MocA Is a Specific Cytidylyltransferase Involved in Molybdopterin Cytosine Dinucleotide Biosynthesis in Escherichia coli. J. Boil. Chem. 2009, 284, 21891-21898. [CrossRef] 
59. Santamaria-Araujo, J.A.; Fischer, B.; Otte, T.; Nimtz, M.; Mendel, R.R.; Wray, V.; Schwarz, G. The Tetrahydropyranopterin Structure of the Sulfur-free and Metal-free Molybdenum Cofactor Precursor. J. Boil. Chem. 2004, 279, 15994-15999. [CrossRef]

60. Wuebbens, M.M.; Rajagopalan, K.V. Investigation of the Early Steps of Molybdopterin Biosynthesis in Escherichia coli through the Use of In Vivo Labeling Studies. J. Boil. Chem. 1995, 270, 1082-1087. [CrossRef]

61. Pitterle, D.M.; Johnson, J.L.; Rajagopalan, K.V. Molybdopterin formation by converting factor of E. coli chlA1. FASEB J. 1990, 4, A1957.

62. Pitterle, D.M.; Rajagopalan, K.V. Two proteins encoded at the chlA locus constitute the converting factor of Escherichia coli chlA1. J. Bacteriol. 1989, 171, 3373-3378. [CrossRef] [PubMed]

63. Pitterle, D.M.; Rajagopalan, K.V. Purification and characterization of the converting factor from E. coli chlA1. FASEB J. 1991, 5, A468.

64. Pitterle, D.M.; Rajagopalan, K.V. The biosynthesis of molybdopterin in Escherichia coli. Purification and characterization of the converting factor. J. Boil. Chem. 1993, 268, 13499-13505.

65. Daniels, J.N.; Wuebbens, M.M.; Rajagopalan, K.V.; Schindelin, H. Crystal Structure of a Molybdopterin Synthase-Precursor Z Complex: Insight into Its Sulfur Transfer Mechanism and Its Role in Molybdenum Cofactor Deficiency. Biochemistry 2008, 47, 615-626. [CrossRef] [PubMed]

66. Rudolph, M.J.; Wuebbens, M.M.; Rajagopalan, K.V.; Schindelin, H. Crystal structure of molybdopterin synthase and its evolutionary relationship to ubiquitin activation. Nat. Genet. 2001, 8, 42-46.

67. Gutzke, G.; Fischer, B.; Mendel, R.R.; Schwarz, G. Thiocarboxylation of Molybdopterin Synthase Provides Evidence for the Mechanism of Dithiolene Formation in Metal-binding Pterins. J. Boil. Chem. 2001, 276, 36268-36274. [CrossRef] [PubMed]

68. Leimkühler, S.; Freuer, A.; Araujo, J.A.S.; Rajagopalan, K.V.; Mendel, R.R. Mechanistic Studies of Human Molybdopterin Synthase Reaction and Characterization of Mutants Identified in Group B Patients of Molybdenum Cofactor Deficiency. J. Boil. Chem. 2003, 278, 26127-26134. [CrossRef]

69. Nichols, J.; Rajagopalan, K.V. Escherichia coli MoeA and MogA. Function in metal incorporation step of molybdenum cofactor biosynthesis. J. Biol. Chem. 2002, 277, 24995-25000. [CrossRef]

70. Nichols, J.D.; Rajagopalan, K.V. In Vitro Molybdenum Ligation to Molybdopterin Using Purified Components. J. Boil. Chem. 2005, 280, 7817-7822. [CrossRef]

71. Kuper, J.; Llamas, Á.; Hecht, H.-J.; Mendel, R.R.; Schwarz, G. Structure of the molybdopterin-bound Cnx1G domain links molybdenum and copper metabolism. Nature 2004, 430, 803-806. [CrossRef]

72. Reschke, S.; Sigfridsson, K.G.; Kaufmann, P.; Leidel, N.; Horn, S.; Gast, K.; Schulzke, C.; Haumann, M.; Leimkühler, S. Identification of a Bis-molybdopterin Intermediate in Molybdenum Cofactor Biosynthesis in Escherichia coli. J. Boil. Chem. 2013, 288, 29736-29745. [CrossRef] [PubMed]

73. Temple, C.A.; Rajagopalan, K.V. Mechanism of Assembly of the Bis(Molybdopterin Guanine Dinucleotide)Molybdenum Cofactor in Rhodobacter sphaeroides Dimethyl Sulfoxide Reductase. J. Boil. Chem. 2000, 275, 40202-40210. [CrossRef] [PubMed]

74. Palmer, T.; Santini, C.-L.; Iobbi-Nivol, C.; Eaves, D.J.; Boxer, D.H.; Giordano, G. Involvement of the narJ and mob gene products in distinct steps in the biosynthesis of the molybdoenzyme nitrate reductase in Escherichia coli. Mol. Microbiol. 1996, 20, 875-884. [CrossRef] [PubMed]

75. Lake, M.W.; Temple, C.A.; Rajagopalan, K.V.; Schindelin, H. The Crystal Structure of the Escherichia coli MobA Protein Provides Insight into Molybdopterin Guanine Dinucleotide Biosynthesis. J. Boil. Chem. 2000, 275, 40211-40217. [CrossRef] [PubMed]

76. Bohmer, N.; Hartmann, T.; Leimkühler, S. The chaperone FdsC for Rhodobacter capsulatus formate dehydrogenase binds the bis-molybdopterin guanine dinucleotide cofactor. FEBS Lett. 2014, 588, 531-537. [CrossRef]

77. Leimkühler, S.; Iobbi-Nivol, C. Bacterial Molybdoenzymes: Chaperones, Assembly and Insertion. FEMS Microbiol. Rev. 2016, 40. [CrossRef]

78. Zupok, A.; Iobbi-Nivol, C.; Mejean, V.; Leimkühler, S. The regulation of Moco biosynthesis and molybdoenzyme gene expression by molybdenum and iron in bacteria. Metallomics 2019, 11, 1602-1624. [CrossRef]

79. Zupok, A.; Gorka, M.; Siemiatkowska, B.; Skirycz, A.; Leimkühler, S. Iron-Dependent Regulation of Molybdenum Cofactor Biosynthesis Genes in Escherichia coli. J. Bacteriol. 2019, 201, e00382-19. [CrossRef] 
80. Mehta, A.P.; Hanes, J.W.; Abdelwahed, S.H.; Hilmey, D.G.; Hänzelmann, P.; Begley, T.P. Catalysis of a New Ribose Carbon-Insertion Reaction by the Molybdenum Cofactor Biosynthetic Enzyme MoaA. Biochemistry 2013, 52, 1134-1136. [CrossRef] [PubMed]

81. Leimkühler, S.; Wuebbens, M.M.; Rajagopalan, K.V. Characterization of Escherichia coli MoeB and Its Involvement in the Activation of Molybdopterin Synthase for the Biosynthesis of the Molybdenum Cofactor. J. Boil. Chem. 2001, 276, 34695-34701. [CrossRef]

82. Schindelin, H. Evolutionary Origin of the Activation Step During Ubiquitin-dependent Protein Degradation. In Protein Degradation: Ubiquitin and the Chemistry of Life; Mayer, R.J., Ciechanover, A., Rechsteiner, M., Eds.; WILEY-VCH: Weinheim, Germany, 2005; pp. 21-43.

83. Lake, M.W.; Wuebbens, M.M.; Rajagopalan, K.V.; Schindelin, H. Mechanism of ubiquitin activation revealed by the structure of a bacterial MoeB-MoaD complex. Nature 2001, 414, 325-329. [CrossRef] [PubMed]

84. Schmitz, J.; Wuebbens, M.M.; Rajagopalan, K.V.; Leimkühler, S. Role of the C-Terminal Gly-Gly Motif of Escherichia Coli MoaD, a Molybdenum Cofactor Biosynthesis Protein with a Ubiquitin Fold. Biochemistry 2007, 46, 909-916. [CrossRef] [PubMed]

85. Tong, Y.; Wuebbens, M.M.; Rajagopalan, K.V.; Fitzgerald, M.C. Thermodynamic Analysis of Subunit Interactions in Escherichia coli Molybdopterin Synthase. Biochemistry 2005, 44, 2595-2601. [CrossRef] [PubMed]

86. Leimkühler, S.; Rajagopalan, K.V. An Escherichia coli NifS-like sulfurtransferase is required for the transfer of cysteine sulfur in the In Vitro synthesis of molybdopterin from precursor Z. J. Biol. Chem. 2001, 276, 22024-22031. [CrossRef]

87. Zhang, W.; Urban, A.; Mihara, H.; Leimkühler, S.; Kurihara, T.; Esaki, N. IscS Functions as a Primary Sulfur-donating Enzyme by Interacting Specifically with MoeB and MoaD in the Biosynthesis of Molybdopterin in Escherichia coli. J. Boil. Chem. 2010, 285, 2302-2308. [CrossRef]

88. Iobbi-Nivol, C.; Leimkühler, S. Molybdenum enzymes, their maturation and molybdenum cofactor biosynthesis in Escherichia coli. Biochim. Biophys. Acta 2013, 1827, 1086-1101. [CrossRef]

89. Dahl, J.U.; Radon, C.; Bühning, M.; Nimtz, M.; Leichert, L.I.; Denis, Y.; Jourlin-Castelli, C.; Iobbi-Nivol, C.; Méjean, V.; Leimkühler, S. The Sulfur Carrier Protein TusA Has a Pleiotropic Role in Escherichia coli That Also Affects Molybdenum Cofactor Biosynthesis. J. Boil. Chem. 2013, 288, 5426-5442. [CrossRef]

90. Kisker, C.; Schindelin, H.; Rees, D.C. Molybdenum-Cofactor-Containing Enzymes: Structure and Mechanism. Annu. Rev. Biochem. 1997, 66, 233-267. [CrossRef]

91. Schumann, S.; Saggu, M.; Möller, N.; Anker, S.D.; Lendzian, F.; Hildebrandt, P.; Leimkühler, S. The Mechanism of Assembly and Cofactor Insertion into Rhodobacter capsulatus xanthine dehydrogenase. J. Boil. Chem. 2008, 283, 16602-16611. [CrossRef]

92. Pinske, C.; Sawers, R.G. A-Type Carrier Protein ErpA Is Essential for Formation of an Active Formate-Nitrate Respiratory Pathway in Escherichia coli K-12. J. Bacteriol. 2011, 194, 346-353. [CrossRef]

93. Boniecki, M.T.; Freibert, S.A.; Mühlenhoff, U.; Lill, R.; Cygler, M. Structure and functional dynamics of the mitochondrial Fe/S cluster synthesis complex. Nat. Commun. 2017, 8, 1287. [CrossRef] [PubMed]

94. Wiedemann, N.; Urzica, E.; Guiard, B.; Müller, H.; Lohaus, C.; E Meyer, H.; Ryan, M.T.; Meisinger, C.; Mühlenhoff, U.; Lill, R.; et al. Essential role of Isd11 in mitochondrial iron-sulfur cluster synthesis on Isu scaffold proteins. EMBO J. 2006, 25, 184-195. [CrossRef] [PubMed]

95. Adam, A.C.; Bornhövd, C.; Prokisch, H.; Neupert, W.; Hell, K. The Nfs1 interacting protein Isd11 has an essential role in Fe/S cluster biogenesis in mitochondria. EMBO J. 2006, 25, 174-183. [CrossRef] [PubMed]

96. Lim, S.C.; Friemel, M.; Marum, J.E.; Tucker, E.J.; Bruno, D.L.; Riley, L.G.; Christodoulou, J.; Kirk, E.; Boneh, A.; DeGennaro, C.M.; et al. Mutations in LYRM4, encoding iron-sulfur cluster biogenesis factor ISD11, cause deficiency of multiple respiratory chain complexes. Hum. Mol. Genet. 2013, 22, 4460-4473. [CrossRef] [PubMed]

97. Maio, N.; Singh, A.; Uhrigshardt, H.; Saxena, N.; Tong, W.H.; Rouault, T.A. Cochaperone binding to LYR motifs confers specificity of iron sulfur cluster delivery. Cell Metab. 2014, 19, 445-457. [CrossRef]

98. Lill, R.; Freibert, S.A. Mechanisms of Mitochondrial Iron-Sulfur Protein Biogenesis. Annu. Rev. Biochem. 2020, 89, 471-499. [CrossRef] 
99. Gervason, S.; Larkem, D.; Ben Mansour, A.; Botzanowski, T.; Müller, C.S.; Pecqueur, L.; Le Pavec, G.; Delaunay-Moisan, A.; Brun, O.; Agramunt, J.; et al. Physiologically relevant reconstitution of iron-sulfur cluster biosynthesis uncovers persulfide-processing functions of ferredoxin-2 and frataxin. Nat. Commun. 2019, 10, 3566. [CrossRef] [PubMed]

100. Lange, H.; Kaut, A.; Kispal, G.; Lill, R. A mitochondrial ferredoxin is essential for biogenesis of cellular iron-sulfur proteins. Proc. Natl. Acad. Sci. USA 2000, 97, 1050-1055. [CrossRef]

101. Sheftel, A.D.; Stehling, O.; Pierik, A.J.; Elsässer, H.P.; Mühlenhoff, U.; Webert, H.; Hobler, A.; Hannemann, F.; Bernhardt, R.; Lill, R. Humans possess two mitochondrial ferredoxins, Fdx1 and Fdx2, with distinct roles in steroidogenesis, heme, and Fe/S cluster biosynthesis. Proc. Natl. Acad. Sci. USA 2010, 107, 11775-11780. [CrossRef]

102. Webert, H.; Freibert, S.A.; Gallo, A.; Heidenreich, T.; Linne, U.; Amlacher, S.; Hurt, E.; Mühlenhoff, U.; Banci, L.; Lill, R. Functional reconstitution of mitochondrial Fe/S cluster synthesis on Isu1 reveals the involvement of ferredoxin. Nat. Commun. 2014, 5, 5013. [CrossRef]

103. Herrero, E.; De La Torre-Ruiz, M.A. Monothiol glutaredoxins: A common domain for multiple functions. Cell. Mol. Life Sci. 2007, 64, 1518-1530. [CrossRef] [PubMed]

104. Rodriguez-Manzaneque, M.T.; Tamarit, J.; Belli, G.; Ros, J.; Herrero, E. Grx5 Is a Mitochondrial Glutaredoxin Required for the Activity of Iron/Sulfur Enzymes. Mol. Boil. Cell 2002, 13, 1109-1121. [CrossRef] [PubMed]

105. Rouhier, N.; Couturier, J.; Johnson, M.K.; Jacquot, J.P. Glutaredoxins: Roles in iron homeostasis. Trends Biochem. Sci. 2010, 35, 43-52. [CrossRef] [PubMed]

106. Dutkiewicz, R.; Nowak, M. Molecular chaperones involved in mitochondrial iron-sulfur protein biogenesis. J. Boil. Inorg. Chem. 2018, 23, 569-579. [CrossRef]

107. Kampinga, H.H.; Craig, E.A. The HSP70 chaperone machinery: J proteins as drivers of functional specificity. Nat. Rev. Mol. Cell Boil. 2010, 11, 579-592. [CrossRef]

108. Andrew, A.J.; Dutkiewicz, R.; Knieszner, H.; Craig, E.A.; Marszalek, J. Characterization of the Interaction between the J-protein Jac1p and the Scaffold for Fe-S Cluster Biogenesis, Isu1p. J. Boil. Chem. 2006, 281, 14580-14587. [CrossRef]

109. Ciesielski, S.J.; Schilke, B.A.; Osipiuk, J.; Bigelow, L.; Mulligan, R.; Majewska, J.; Joachimiak, A.; Marszalek, J.; Craig, E.A.; Dutkiewicz, R. Interaction of J-Protein Co-Chaperone Jac1 with Fe-S Scaffold Isu Is Indispensable In Vivo and Conserved in Evolution. J. Mol. Boil. 2012, 417. [CrossRef]

110. Lill, R. From the discovery to molecular understanding of cellular iron-sulfur protein biogenesis. Boil. Chem. 2020. [CrossRef]

111. Beilschmidt, L.K.; De Choudens, S.O.; Fournier, M.; Sanakis, I.; Hograindleur, M.-A.; Clémancey, M.; Blondin, G.; Schmucker, S.; Eisenmann, A.; Weiss, A.; et al. ISCA1 is essential for mitochondrial $\mathrm{Fe}_{4} \mathrm{~S}_{4}$ biogenesis In Vivo. Nat. Commun. 2017, 8, 15124. [CrossRef]

112. Gelling, C.; Dawes, I.W.; Richhardt, N.; Lill, R.; MühlenhoffU. Mitochondrial Iba57p Is Required for Fe/S Cluster Formation on Aconitase and Activation of Radical SAM Enzymes. Mol. Cell. Boil. 2007, 28, 1851-1861. [CrossRef]

113. Muhlenhoff, U.; Richter, N.; Pines, O.; Pierik, A.J.; Lill, R. Specialized Function of Yeast Isa1 and Isa2 Proteins in the Maturation of Mitochondrial [4Fe-4S] Proteins. J. Boil. Chem. 2011, 286, 41205-41216. [CrossRef]

114. Sheftel, A.D.; Wilbrecht, C.; Stehling, O.; Niggemeyer, B.; Elsasser, H.P.; Muhlenhoff, U.; Lill, R. The human mitochondrial ISCA1, ISCA2, and IBA57 proteins are required for [4Fe-4S] protein maturation. Mol. Biol. Cell. 2012, 23, 1157-1166. [CrossRef] [PubMed]

115. Banci, L.; Brancaccio, D.; Ciofi-Baffoni, S.; Del Conte, R.; Gadepalli, R.; Mikolajczyk, M.; Neri, S.; Piccioli, M.; Winkelmann, J. [2Fe-2S] cluster transfer in iron-sulfur protein biogenesis. Proc. Natl. Acad Sci. USA 2014, 111, 6203-6208. [CrossRef] [PubMed]

116. Brancaccio, D.; Gallo, A.; Mikolajczyk, M.; Zovo, K.; Palumaa, P.; Novellino, E.; Piccioli, M.; Ciofi-Baffoni, S.; Banci, L. Formation of [4Fe-4S] Clusters in the Mitochondrial Iron-Sulfur Cluster Assembly Machinery. J. Am. Chem. Soc. 2014, 136, 16240-16250. [CrossRef] [PubMed]

117. Brancaccio, D.; Gallo, A.; Piccioli, M.; Novellino, E.; Ciofi-Baffoni, S.; Banci, L. [4Fe-4S] Cluster Assembly in Mitochondria and Its Impairment by Copper. J. Am. Chem. Soc. 2017, 139, 719-730. [CrossRef] [PubMed]

118. Gourdoupis, S.; Nasta, V.; Calderone, V.; Ciofi-Baffoni, S.; Banci, L. IBA57 Recruits ISCA2 to Form a [2Fe-2S] Cluster-Mediated Complex. J. Am. Chem. Soc. 2018, 140, 14401-14412. [CrossRef] 
119. Nasta, V.; Da Vela, S.; Gourdoupis, S.; Ciofi-Baffoni, S.; Svergun, D.I.; Banci, L. Structural properties of [2Fe-2S] ISCA2-IBA57: A complex of the mitochondrial iron-sulfur cluster assembly machinery. Sci. Rep. 2019, 9, 1-12. [CrossRef]

120. Maio, N.; Rouault, T.A. Outlining the Complex Pathway of Mammalian Fe-S Cluster Biogenesis. Trends Biochem. Sci. 2020, 45, 411-426. [CrossRef]

121. Netz, D.J.; Mascarenhas, J.; Stehling, O.; Pierik, A.J.; Lill, R. Maturation of cytosolic and nuclear iron-sulfur proteins. Trends Cell Boil. 2014, 24, 303-312. [CrossRef]

122. Paul, V.D.; Lill, R. Biogenesis of cytosolic and nuclear iron-sulfur proteins and their role in genome stability. Biochim. Biophys. Acta 2015, 1853, 1528-1539. [CrossRef]

123. Gerber, S.; Comellas-Bigler, M.; Goetz, B.A.; Locher, K.P. Structural Basis of Trans-Inhibition in a Molybdate/Tungstate ABC Transporter. Science 2008, 321, 246-250. [CrossRef]

124. Biederbick, A.; Stehling, O.; Rosser, R.; Niggemeyer, B.; Nakai, Y.; Elsasser, H.-P.; Lill, R. Role of Human Mitochondrial Nfs1 in Cytosolic Iron-Sulfur Protein Biogenesis and Iron Regulation. Mol. Cell. Boil. 2006, 26, 5675-5687. [CrossRef] [PubMed]

125. Stehling, O.; Netz, D.J.; Niggemeyer, B.; Rosser, R.; Eisenstein, R.S.; Puccio, H.; Pierik, A.J.; Lill, R. Human Nbp35 Is Essential for both Cytosolic Iron-Sulfur Protein Assembly and Iron Homeostasis. Mol. Cell. Boil. 2008, 28, 5517-5528. [CrossRef] [PubMed]

126. Stehling, O.; Jeoung, J.-H.; Freibert, S.A.; Paul, V.D.; Bänfer, S.; Niggemeyer, B.; Rösser, R.; Dobbek, H.; Lill, R. Function and crystal structure of the dimeric P-loop ATPase CFD1 coordinating an exposed [4Fe-4S] cluster for transfer to apoproteins. Proc. Natl. Acad. Sci. USA 2018, 115, E9085-E9094. [CrossRef] [PubMed]

127. Netz, D.J.; Stümpfig, M.; Doré, C.; Mühlenhoff, U.; Pierik, A.J.; Lill, R. Tah18 transfers electrons to Dre2 in cytosolic iron-sulfur protein biogenesis. Nat. Methods 2010, 6, 758-765. [CrossRef] [PubMed]

128. Netz, D.J.; Genau, H.M.; Weiler, B.D.; Bill, E.; Pierik, A.J.; Lill, R. The conserved protein Dre2 uses essential [2Fe-2S] and [4Fe-4S] clusters for its function in cytosolic iron-sulfur protein assembly. Biochem. J. 2016, 473, 2073-2085. [CrossRef]

129. Banci, L.; Ciofi-Baffoni, S.; Gajda, K.; Muzzioli, R.; Peruzzini, R.; Winkelmann, J. N-terminal domains mediate [2Fe-2S] cluster transfer from glutaredoxin-3 to anamorsin. Nat. Methods 2015, 11, 772-778. [CrossRef]

130. Frey, A.G.; Palenchar, D.J.; Wildemann, J.D.; Philpott, C.C. A Glutaredoxin·BolA Complex Serves as an Iron-Sulfur Cluster Chaperone for the Cytosolic Cluster Assembly Machinery. J. Boil. Chem. 2016, 291, 22344-22356. [CrossRef]

131. Haunhorst, P.; Hanschmann, E.-M.; Bräutigam, L.; Stehling, O.; Hoffmann, B.; Mühlenhoff, U.; Lill, R.; Berndt, C.; Lillig, C.H. Crucial function of vertebrate glutaredoxin 3 (PICOT) in iron homeostasis and hemoglobin maturation. Mol. Boil. Cell 2013, 24, 1895-1903. [CrossRef]

132. Banci, L.; Camponeschi, F.; Ciofi-Baffoni, S.; Muzzioli, R. Elucidating the Molecular Function of Human BOLA2 in GRX3-Dependent Anamorsin Maturation Pathway. J. Am. Chem. Soc. 2015, 137, 16133-16143. [CrossRef]

133. Banci, L.; Ciofi-Baffoni, S.; Mikolajczyk, M.; Winkelmann, J.; Bill, E.; Pandelia, M.-E. Human anamorsin binds [2Fe-2S] clusters with unique electronic properties. JBIC J. Boil. Inorg. Chem. 2013, 18, 883-893. [CrossRef] [PubMed]

134. Zhang, Y.; Lyver, E.R.; Nakamaru-Ogiso, E.; Yoon, H.; Amutha, B.; Lee, D.-W.; Bi, E.; Ohnishi, T.; Daldal, F.; Pain, D.; et al. Dre2, a Conserved Eukaryotic Fe/S Cluster Protein, Functions in Cytosolic Fe/S Protein Biogenesis. Mol. Cell. Boil. 2008, 28, 5569-5582. [CrossRef] [PubMed]

135. Gari, K.; Ortiz, A.M.L.; Borel, V.; Flynn, H.R.; Skehel, J.M.; Boulton, S.J. MMS19 Links Cytoplasmic Iron-Sulfur Cluster Assembly to DNA Metabolism. Science 2012, 337, 243-245. [CrossRef] [PubMed]

136. Srinivasan, V.; Netz, D.J.; Webert, H.; Mascarenhas, J.; Pierik, A.J.; Michel, H.; Lill, R. Structure of the Yeast WD40 Domain Protein Cia1, a Component Acting Late in Iron-Sulfur Protein Biogenesis. Struct. 2007, 15, 1246-1257. [CrossRef] [PubMed]

137. Hänzelmann, P.; Hernandez, H.L.; Menzel, C.; García-Serres, R.; Huynh, B.H.; Johnson, M.K.; Mendel, R.R.; Schindelin, H. Characterization of MOCS1A, an Oxygen-sensitive Iron-Sulfur Protein Involved in Human Molybdenum Cofactor Biosynthesis. J. Boil. Chem. 2004, 279, 34721-34732. [CrossRef] [PubMed]

138. Reiss, J.; Christensen, E.; Kurlemann, G.; Zabot, M.-T.; Dorche, C. Genomic structure and mutational spectrum of the bicistronic MOCS1 gene defective in molybdenum cofactor deficiency type A. Hum. Genet. 1998, 103, 639-644. [CrossRef] [PubMed] 
139. Teschner, J.; Lachmann, N.; Schulze, J.; Geisler, M.; Selbach, K.; Santamaria-Araujo, J.; Balk, J.; Mendel, R.; Bittner, F. A novel role for Arabidopsis mitochondrial ABC transporter ATM3 in molybdenum cofactor biosynthesis. Plant Cell 2010, 22, 468-480. [CrossRef]

140. Stallmeyer, B.; Coyne, K.E.; Wuebbens, M.M.; Johnson, J.L.; Rajagopalan, K.V.; Mendel, R.R. The cDNA Sequence of MOCS3, Human Molybdopterin Synthase Sulfurylase; GenBank: National Center for Biotechnology Information: Bethesda, MD, USA, 1998; Accession Number AF102544.

141. Mendel, R.; Schwarz, G. Molybdenum cofactor biosynthesis in plants and humans. Coord. Chem. Rev. 2011, 255, 1145-1158. [CrossRef]

142. Matthies, A.; Nimtz, A.M.; Leimkühler, S. Molybdenum Cofactor Biosynthesis in Humans: Identification of a Persulfide Group in the Rhodanese-like Domain of MOCS3 by Mass Spectrometry. Biochemistry 2005, 44, 7912-7920. [CrossRef]

143. Marelja, Z.; Chowdhury, M.; Dosche, C.; Hille, C.; Baumann, O.; Löhmannsröben, H.-G.; Leimkühler, S. The L-Cysteine Desulfurase NFS1 Is Localized in the Cytosol where it Provides the Sulfur for Molybdenum Cofactor Biosynthesis in Humans. PLoS ONE 2013, 8, e60869. [CrossRef]

144. Marelja, Z.; Stöcklein, W.; Nimtz, M.; Leimkühler, S. A novel role for human Nfs1 in the cytoplasm: Nfs1 acts as a sulfur donor for MOCS3, a protein involved in molybdenum cofactor biosynthesis. J. Boil. Chem. 2008, 283, 25178-25185. [CrossRef] [PubMed]

145. Stallmeyer, B.; Schwarz, G.; Schulze, J.; Nerlich, A.; Reiss, J.; Kirsch, J.; Mendel, R. The neurotransmitter receptor-anchoring protein gephyrin reconstitutes molybdenum cofactor biosynthesis in bacteria, plants, and mammalian cells. Proc. Natl. Acad. Sci. USA 1999, 96, 1333-1338. [CrossRef] [PubMed]

146. Belaidi, A.A.; Schwarz, G. Metal insertion into the molybdenum cofactor: Product-substrate channelling demonstrates the functional origin of domain fusion in gephyrin. Biochem. J. 2013, 450, 149-157. [CrossRef] [PubMed]

147. Krausze, J.; Hercher, T.W.; Zwerschke, D.; Kirk, M.L.; Blankenfeldt, W.; Mendel, R.R.; Kruse, T. The functional principle of eukaryotic molybdenum insertases. Biochem. J. 2018, 475, 1739-1753. [CrossRef] [PubMed]

148. Hille, R.; Nishino, T.; Bittner, F. Molybdenum enzymes in higher organisms. Coord. Chem. Rev. 2011, 255, 1179-1205. [CrossRef] [PubMed]

149. Wahl, R.C.; Rajagopalan, K.V. Evidence for the inorganic nature of the cyanolyzable sulfur of molybdenum hydroxylases. J. Boil. Chem. 1982, 257, 1354-1359.

150. Hille, R. The Mononuclear Molybdenum Enzymes. Chem. Rev. 1996, 96, 2757-2816. [CrossRef]

151. Bittner, F.; Oreb, M.; Mendel, R.R. ABA3 Is a Molybdenum Cofactor Sulfurase Required for Activation of Aldehyde Oxidase and Xanthine Dehydrogenase in Arabidopsis thaliana. J. Boil. Chem. 2001, 276, 40381-40384. [CrossRef] [PubMed]

152. Wollers, S.; Heidenreich, T.; Zarepour, M.; Zachmann, D.; Kraft, C.; Zhao, Y.; Mendel, R.R.; Bittner, F. Binding of Sulfurated Molybdenum Cofactor to the C-terminal Domain of ABA3 fromArabidopsis thalianaProvides Insight into the Mechanism of Molybdenum Cofactor Sulfuration. J. Boil. Chem. 2008, 283, 9642-9650. [CrossRef]

153. Lehrke, M.; Rump, S.; Heidenreich, T.; Wissing, J.; Mendel, R.R.; Bittner, F. Identification of persulfide-binding and disulfide-forming cysteine residues in the NifS-like domain of the molybdenum cofactor sulfurase ABA3 by cysteine-scanning mutagenesis. Biochem. J. 2012, 441, 823-839. [CrossRef]

(C) 2020 by the authors. Licensee MDPI, Basel, Switzerland. This article is an open access article distributed under the terms and conditions of the Creative Commons Attribution (CC BY) license (http://creativecommons.org/licenses/by/4.0/). 